\title{
Recommendation of RILEM TC 258-AAA: RILEM AAR- 12: determination of binder combinations for non-reactive mix design or the resistance to alkali-silica reaction of concrete mixes using concrete prisms $-60{ }^{\circ} \mathrm{C}$ test method with alkali supply
}

\author{
Ingmar Borchers
}

Received: 27 October 2020/ Accepted: 12 March 2021/Published online: 25 October 2021

(C) RILEM 2021

\begin{abstract}
The RILEM AAR-12 concrete prism test is a performance test method for testing aggregate combinations together with various binder combinations (i.e. composite cements or pure Portland cements + Supplementary Cementitious Materials; SCMs). This test method is essentially the same as RILEM AAR-11, except that the storage conditions were modified to evaluate aggregates and concrete compositions for concrete road pavements on Federal highways to avoid ASR damage, especially regarding the impact of de-icing salts and agents. It is based on a method developed by the German Road and Transportation Research Association.
\end{abstract}

Keywords Alkali-silica reaction - Performance testing method $\cdot$ External alkali supply

This recommendation has been prepared by a working group within RILEM TC 258-AAA. The recommendation has been reviewed and approved by all members of the TC.

Chair: Børge Johannes Wigum

Deputy Chair: Jan Lindgård

TC Members: Mark G. Alexander, Mario Berra, Ingmar Borchers, Maarten Broekmans, Rene Brueckner, João Custódio, Vinh Dao, Mario de Rooij, Klaartje de Weerdt, Josée Duchesne, Rui Miguel Ferreira, Benoît Fournier, Sue Freitag, Ricardo Garcia-Roves Loza, Eric Giannini, Colin Giebson, Michal A. Glinicki, R. Doug Hooton, Jason H. Ideker, Patricija Kara de Maeijer, Yuichiro Kawabata, Stefan Krispel, Selmo C. Kuperman, Andreas Leemann, Lech Lewczuk, Jan Lindgård,

\section{Foreword}

The $60{ }^{\circ} \mathrm{C}$ concrete prism method RILEM AAR-4.1 [1] was initially developed by RILEM following an international trial. This trial showed that the method can reliably differentiate reactive and non-reactive combinations for a range of aggregate compositions from around the world. It also takes into account the experience of the European PARTNER programme [2]. It is part of a suite of test methods for aggregate reactivity developed by RILEM; the combined use of this suite of tests for aggregate assessment is described in RILEM AAR-0 [3]. The RILEM AAR-12 method is developed from an AFNOR performance test for concrete mixtures $[9,10]$ and is based on the aggregate test method, RILEM AAR-4.1 [1] and the $60{ }^{\circ} \mathrm{C}$ performance test method RILEM AAR-11 [4].

The $60{ }^{\circ} \mathrm{C}$ performance test method RILEM AAR12 has been developed for testing aggregate combinations together with various binder combinations (i.e.

Tung Chai Ling, Qing-Feng Liu, Renaud-Pierre Martin, Esperanza Menendez Mendez, Birgit Meng, Urs Müller, Christoph Müller, Bård M. Pedersen, Gilles Plusquellec, Terje F. Rønning, Leandro Sanchez, Antonio Santos Silva, Ignacio Segura, Katrin Seyfarth, Gintautas Skripkiunas, Zhenguo Shi, Ian Sims, Suvimol Sujjavanich, Michael D. A. Thomas, Børge Johannes wigum, (late) Jonathan Wood, Kazuo Yamada.

I. Borchers $(\bowtie)$

VDZ Technology gGmbH, Toulouser Allee 71,

40476 Duesseldorf, Germany

e-mail: ingmar.borchers@vdz-online.de 
composite cements or CEM I cements + supplementary cementitious materials; SCMs). Performance testing of concrete durability properties including the resistance to alkali-silica reaction offers an alternative to prescriptive specification-based regulations, but needs to be adopted together with adequate acceptance testing criteria and within a system of conformity assessment, including suppliers' responsibility of declaration of product characteristics. Examples of adoption of some of the principles in this document into national provisions are provided in Sect. 9.

The $60{ }^{\circ} \mathrm{C}$ performance test method RILEM AAR12 is used to mitigate a damaging ASR in concrete motorways in Germany [11, 12], but it is also applied to concrete for railway sleepers [13]. This test method is considered more reliable in identifying alkalireactive aggregates combinations for concrete motorways than the reference concrete test method with fog chamber storage at $40{ }^{\circ} \mathrm{C}$ and the accelerated mortar bar test at $80{ }^{\circ} \mathrm{C}$ [6]. Suggestions for limit values are given in $[7,8]$.

\section{Scope}

The method covers the measurement of expansion produced by alkali-aggregate reaction of concrete prisms stored in an environment which accelerates the alkali-silica reaction (ASR). It covers environmental exposure conditions with the impact of de-icing salts and agents (e. g. Environment class E3 according to RILEM AAR-7.1 [5] that covers concrete that is exposed to extraneous moisture and de-icing salts, seawater or salt spray). It is essentially the same as RILEM method AAR-11 (concrete prism test at $60{ }^{\circ} \mathrm{C}$ ), but the storage conditions have been modified to evaluate the impact of de-icing salts and agents. It is based on a method issued by the German Road and Transportation Research Association (FGSV) for evaluating the potential for deleterious ASR in concrete proposed for use in pavements of highways [11]. The FGSV method is used in conjunction with the General Circular on Road Construction (ARS) No. 04/2013 [12] to test aggregates and concrete compositions for concrete road pavements on Federal highways to avoid ASR damage (see AAR-12, Sect. 9.3, Germany).

Procedures include the following applications for the performance assessment of combinations of aggregates and cement/binders (incl. maximum CEM I (EN 197-1) content) at various or specific alkali content(s) and for the assessment of the ASRresistance of concrete mixtures:

Application 1: AAR-12.1: Assessment of how SCM content may reduce ASR susceptibility of an aggregate combination: enabling the use of a specific reactive aggregate product together with critical binder combination(s) (minimum binder requirements) for producing non-reactive concrete

Application 2: AAR-12.2: Assessment of how available binder alkali content can be reduced by SCMs: enabling the determination of the required general binder composition together with a regional worst-case aggregate combination for producing non-reactive concrete (within that region)

Application 3: AAR-12.3: Assessment of the ASRresistance of specific concrete compositions to verify their suitability in a performance test

AAR-12.1 (Sect. 5) may typically meet the needs of an aggregate supplier to identify appropriate binder combination(s), including the maximum alkali content for which such combinations could be used, to avoid deleterious ASR in concrete incorporating this supplier's product.

AAR-12.2 (Sect. 6) may typically meet the needs of suppliers of composite cement or SCMs to identify appropriate binder combinations to avoid deleterious ASR in concrete incorporating a reference (worstcase) aggregate (i.e. most reactive aggregate in the region or market area), thus allowing the use of all aggregate sources within that larger market area). This concept may also be adopted for the development of regional/national design rules when applying reactive aggregate combinations, using a mitigation measure of applying certain types of composite cement or additions.

AAR-12.3 (Sect. 7) may typically meet the needs of suppliers of concrete products or construction companies to evaluate and demonstrate the resistance to ASR of a specific concrete mixture (job mix).

The scope does not include in the current stage aggregate combinations under conditions when intended or non-intended changes in concentration between individual fractions may introduce pessimum effects. Hence, the application of the present 
document assumes that the aggregates have been subjected to petrographic examination and/or other investigations enabling adequate classification or characterisation to avoid unforeseen pessimum behavior when combining aggregate fractions.

Note 1 Pessimum behavior is obtained in mortar and concrete when maximum expansion occurs for a specific proportion of reactive material in an aggregate product, while reduced expansion is observed when both more or less of that specific proportion of reactive material is used. It has been questioned whether the ASR susceptibility of some of these aggregates is adequately assessed by expansion/performance testing or whether other criteria apply. This issue is still subject to research.

Note 2 The method has been developed for normal weight aggregates and has not been validated for lightweight aggregates (oven dry particle density less than $2000 \mathrm{~kg} / \mathrm{m}^{3}$ ), heavy weight aggregates (oven dry particle density greater than $3500 \mathrm{~kg} / \mathrm{m}^{3}$ ), or recycled aggregates of any density.

\section{Principle}

Concrete test prisms are prepared with the selected aggregate and binder combination(s). Sodium hydroxide is added to the mixing water when necessary to enhance the alkali level (alkali boosting). The prisms are then stored in warm $\left(60{ }^{\circ} \mathrm{C}\right)$ and humid conditions for 6 months to promote ASR. Measurements are made after a 28-day pre-storage period and after each alternating storage cycle to determine whether any expansion has occurred.

In AAR-12.1, a selected aggregate fraction or combination (Application 1/Sect. 5.1.3) is tested together with a binder candidate, to establish safe use of that aggregate. Testing is performed from a "conservative view" within the target range of use of the aggregate (its range of expected variations): the applicability of the test results is limited to the maximum content of the aggregate fraction/combination assumed to be most susceptible in the test. Ranking of such susceptibility may be established using RILEM AAR-10 with CEM I (EN 197-1), AAR3.2 and AAR-4.1, from other methods, or from practical experience. For reactive aggregates of identical mineralogy in a combination, the finer fraction may react faster, but the coarser fraction may still expand more; however, this may depend on mineralogy.

The alkali level for which the aggregate is tested is the sum of the alkalis from the cement clinker contribution and that from any chemical admixtures and other alkali-releasable sources. Several alkali boosting levels may be tested to investigate the effect of later modification of the concrete composition or changes in the alkali contribution from its constituents. If needed for the testing objectives, additional levels of $\mathrm{SCM}(\mathrm{s})$ content are added to the investigation. Hence, the main variable (scope of testing) may be the level of alkali or level of such SCM in the range of mix designs. The test output will be a maximum alkali level or a minimum SCM content, separately or in combination, to use with this aggregate combination (see Figs. 5 and 6 for a visual example). For the selected aggregate combination, the investigation will typically include three to five levels of SCM or alkali content (or more if both parameters are combined).

Note 3 Some aggregates may contain and release alkalis; see Sect. 10.

An example of the use of Application 1 is when a contractor needs to use a reactive aggregate. The contractor then needs to determine a minimum level of a specific SCM to be employed at a maximum cement alkali level.

In AAR-12.2, a selected cement or binder composition is tested together with a reference or worst-case scenario aggregate combination and grading (Application 2/Sect. 6.1.3), to establish a generic cement/ binder solution in the area of interest. The binder combination reflects a selected level/ratio of cement clinker and the intended minimum level/ratio, type and source of $\operatorname{SCM}(\mathrm{s})$.

The alkali level for which the aggregate is tested is the sum of the alkalis from the cement clinker contribution and that from any chemical admixtures and other alkali-releasable sources. Several alkali boosting levels may be tested to investigate the effect of later modification of the concrete composition or changes in the alkali contribution from its constituents. The test output will be a maximum level of alkali content for which the binder composition is validated for use in combination with aggregates that are available (or intended for use) in the area. For the 
selected binder combination(s), the investigation will typically include three to five levels of alkali content.

An example of the use of Application 2 is when a cement producer needs to develop "low-alkali effective cement" (e.g. pozzolan containing cement-or determine and declare a maximum level of that cement product to be used-together with generally available ASR-susceptible aggregates within a region or application segment. The producer then needs to determine the maximum cement (alkali) content and minimum level of a (specific) SCM to be employed.

In both AAR-12.1 and AAR-12.2:

- A standard water-to-binder ratio (w/b) of 0.48 is specified that is intended to maximize the concrete prism expansion during the test, irrespective of the $\mathrm{w} / \mathrm{b}$ used in field.

- Restrictions for validation apply to the properties of the SCM(s) (type/source); the output from the investigation is valid for $\mathrm{SCM}(\mathrm{s})$ of the same type and source as investigated.

- Interpolation of high/low alkali content and content of the specific SCM is enabled in line with a conservative approach, as described below.

Note 4 Changing the $\mathrm{w} / \mathrm{b}$ from the specified value will influence the response of test samples to the test conditions and introduce uncertainties versus established laboratory/field relationships. Hence, the specified $\mathrm{w} / \mathrm{b}$ for testing is selected in a way that corresponds to, or is conservative with respect to, the application of the same material combinations under field conditions.

In AAR-12.1, expansion test results are plotted against the content level of the SCM; alternatively, test results may be presented as separate charts for various alkali levels or, for a fixed SCM content, as a function of the levels of alkali content (SCM content is zero in the case of using CEM I (EN 197-1) alone for alkali threshold determination). The linear intersection with a pre-determined expansion limit value (test criterion) determines the minimum level of the SCM and/or maximum alkali content, respectively.

In AAR-12.2, expansion test results are plotted against the alkali content level. The linear intersection with a pre-determined expansion limit value (test criterion) determines the maximum critical alkali content level of the cement/binder combination together with the reference aggregate.
In AAR-12.3, a selected concrete mix is tested to verify its ASR-resistance. The result is limited to the specific aggregate combination, cement type, alkali content of the cement, and mixture proportions used in the test.

\section{Apparatus}

\subsection{Sieves}

Aperture sizes (mm) 22.4, 16.0, 8.0, 4.0, 2.0, 1.0, 0.5, 0.25 and 0.125 .or ASTM equivalents [14].

\subsection{Moulds}

Moulds made of steel or other hard surface material, suitable for casting concrete prisms of lengths $250 \pm 50 \mathrm{~mm}$ and cross-section $75 \pm 5 \mathrm{~mm}$. The moulds shall have the facility for casting stainless steel reference studs into the centers of the end faces of the prisms.

Note 5 Shorter prisms may influence the relative expansion and shall be specially noted in the report. In some cases it might be necessary to use bigger prisms (e.g. dam concrete with bigger aggregate size). In this case the standard size prisms should be tested additionally for comparison and the limit value shall be verified.

Note 6 A smaller cross-sectional area should not be used because it will increase the surface-to-volume ratio and increase the alkali leaching from the test specimens during the test.

\subsection{Length comparator}

The length comparator should be such as to accommodate the shape of the reference studs in the prism and shall incorporate a gauge mounted rigidly in a vertical or horizontal orientation (Fig. 1). The length change measuring device shall have a resolution of $0.001 \mathrm{~mm}$ or better and a maximum permissible error of $\pm 0.005 \mathrm{~mm}$.

\subsection{Reference studs}

These shall be compatible with the length comparator (4.3) and preferably mounted via the moulds prior to 
casting of the test specimens, rather than affixed to the surface of the specimen with glue or epoxy. Examples for the reference studs are given in AFNOR NF P 18454 [9], Figure B.2 and Fig. 2.

The reference studs shall be made out of working material 1.4571 to avoid corrosion.

Note 7 Some glue components may not be sufficiently volume-stable under the moisture and temperature conditions of the test.

\subsection{Standard length gauge}

This shall consist of an Invar ${ }^{\circledR}$ rod with ends machined to the same shape as the contact end of the reference studs.
4.6 Weighing device for weighing the prisms

The weighing device shall be suitable for weighing specimens to the nearest $1 \mathrm{~g}$.

\subsection{Concrete mixing and casting equipment}

Equipment shall be suitable for mixing batches (EN 480-1 [15]) and vibrating of the moulds (EN 12390-2 [16] or ASTM C 192/C192M [17]). Concrete with a slump value $\leq 100 \mathrm{~mm}$ should be vibrated. Concrete with a slump value $>100 \mathrm{~mm}$ should be compacted manually by rodding.
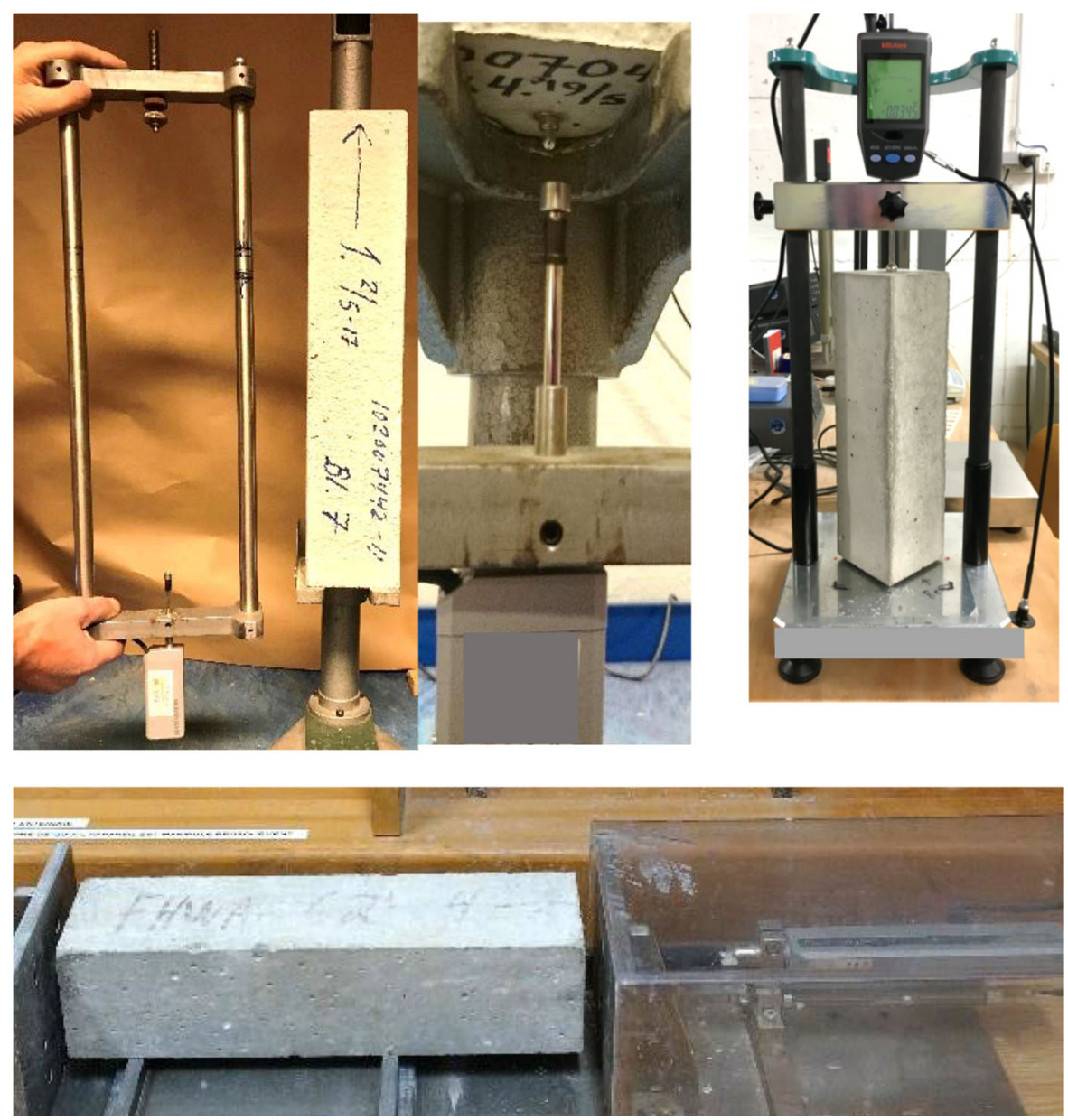

Fig. 1 Example of length comparator with gauge mounted rigidly in a vertical orientation (above) and horizontally (below) 

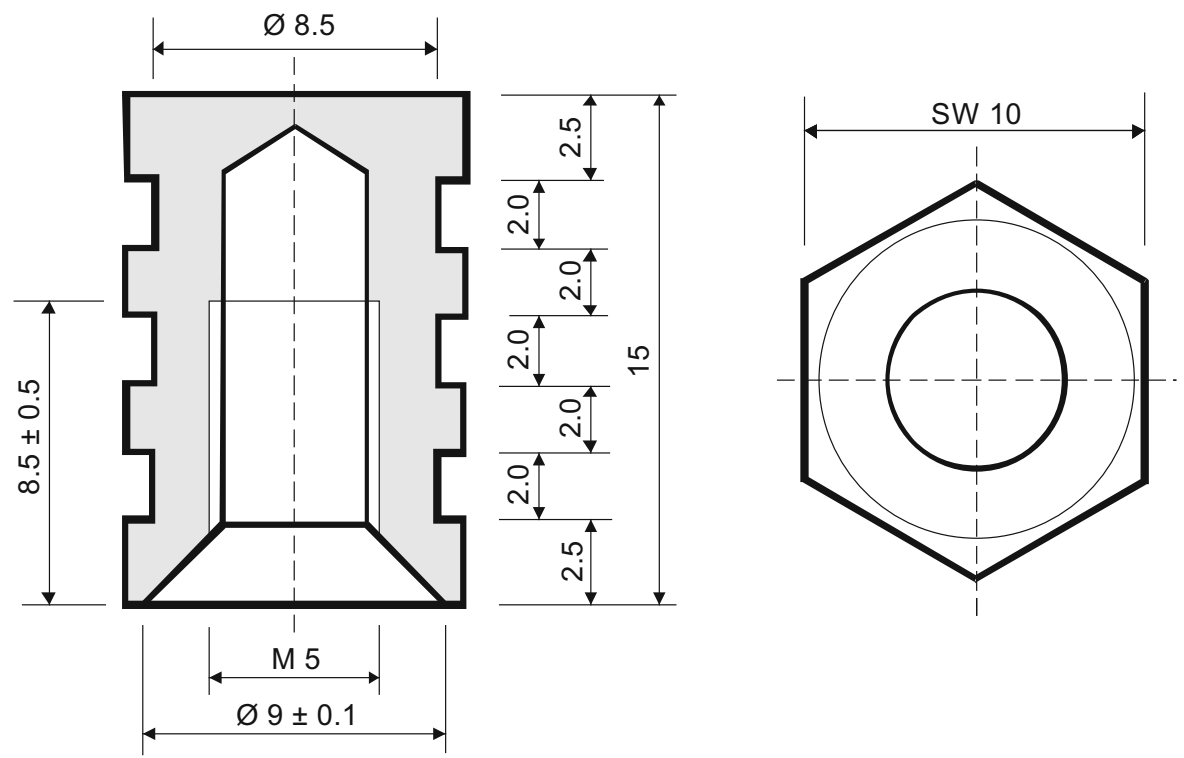

Fig. 2 Example for reference studs

\subsection{Casting, curing and measuring environment}

For casting, a room maintained at $20 \pm 2{ }^{\circ} \mathrm{C}$ shall be used (see also Sect. 8.1).

The specimens shall be cured in a moist environment held at $20 \pm 2{ }^{\circ} \mathrm{C}$ and not less than $90 \%$ relative humidity.

Measurements of weight and length (including initial measurements made immediately after demoulding) shall be made in a room maintained at $20 \pm 2{ }^{\circ} \mathrm{C}$ and relative humidity not less than $50 \%$ (see also Sect. 8.1).

\subsection{Specimen storage}

The specimens shall be stored in sealable containers within a reactor (Fig. 3) generating $60 \pm 2{ }^{\circ} \mathrm{C}$ and a relative humidity as close as possible to $100 \%$. The water level in the bottom of the reactor is approximately $190 \mathrm{~mm}$.

Figure 4 shows a suitable sealable container designed for 3 prisms. The water level (see note 8) at the bottom is $35 \pm 5 \mathrm{~mm}$ and the prisms are located $15 \pm 5 \mathrm{~mm}$ above the water. The standard containers are designed to contain 3 specimens. An alternative container suitable for 6 specimens can be used;
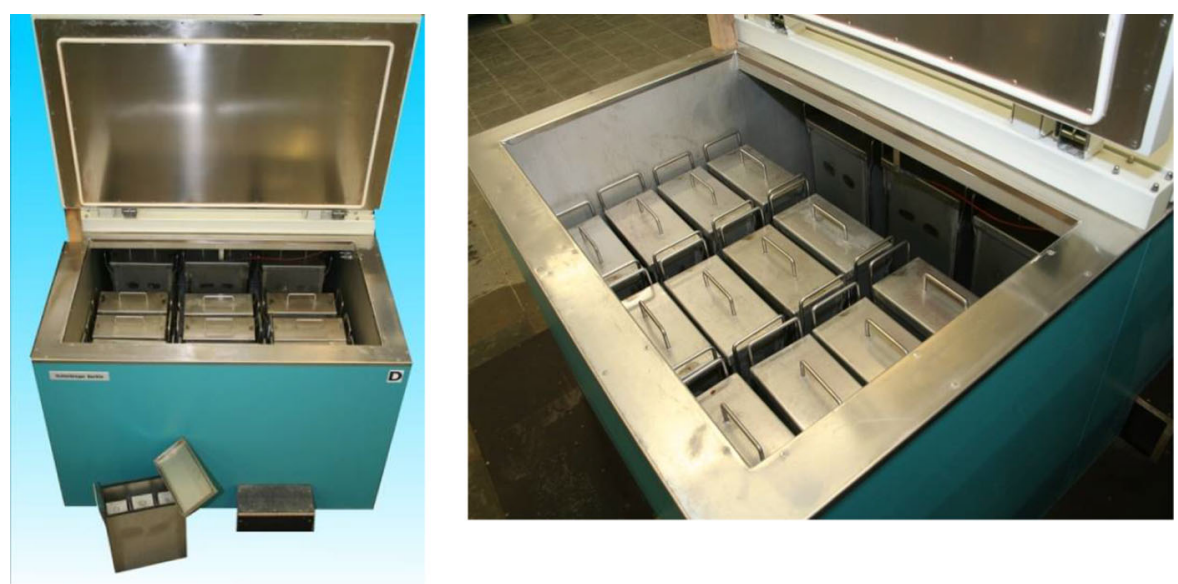

Fig. 3 Reactor generating $60{ }^{\circ} \mathrm{C}$ and $100 \%$ humidity

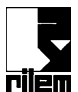


appropriate dimensions would be $400 \times 280 \times 230 \mathrm{~mm}$.

Note 8 In (mainly research) cases where any alkali loss from the concrete prisms during testing is being monitored by periodically analysing the water in the bottom of the sealable containers, consideration should be given to the use of deionised water.

\subsection{Dryer}

Dryer with an air supply (pre-heated to $60 \pm 5^{\circ} \mathrm{C}$ ), relative humidity $<10 \%$. The volume of the dryer and the number of shelves should be chosen so as to allow the samples to dry evenly on each side-spacing between the samples should ensure free air circulation.

\subsection{Plastic container}

Plastic container with lid made of plastic resistant to prolonged exposure to the $\mathrm{NaCl}$ solution, designed to prevent loss or increase in humidity during sample storage. Example with internal dimension: Length $\times$ Width $\times$ Height $=350 \times 270 \times 220 \mathrm{~mm}$.
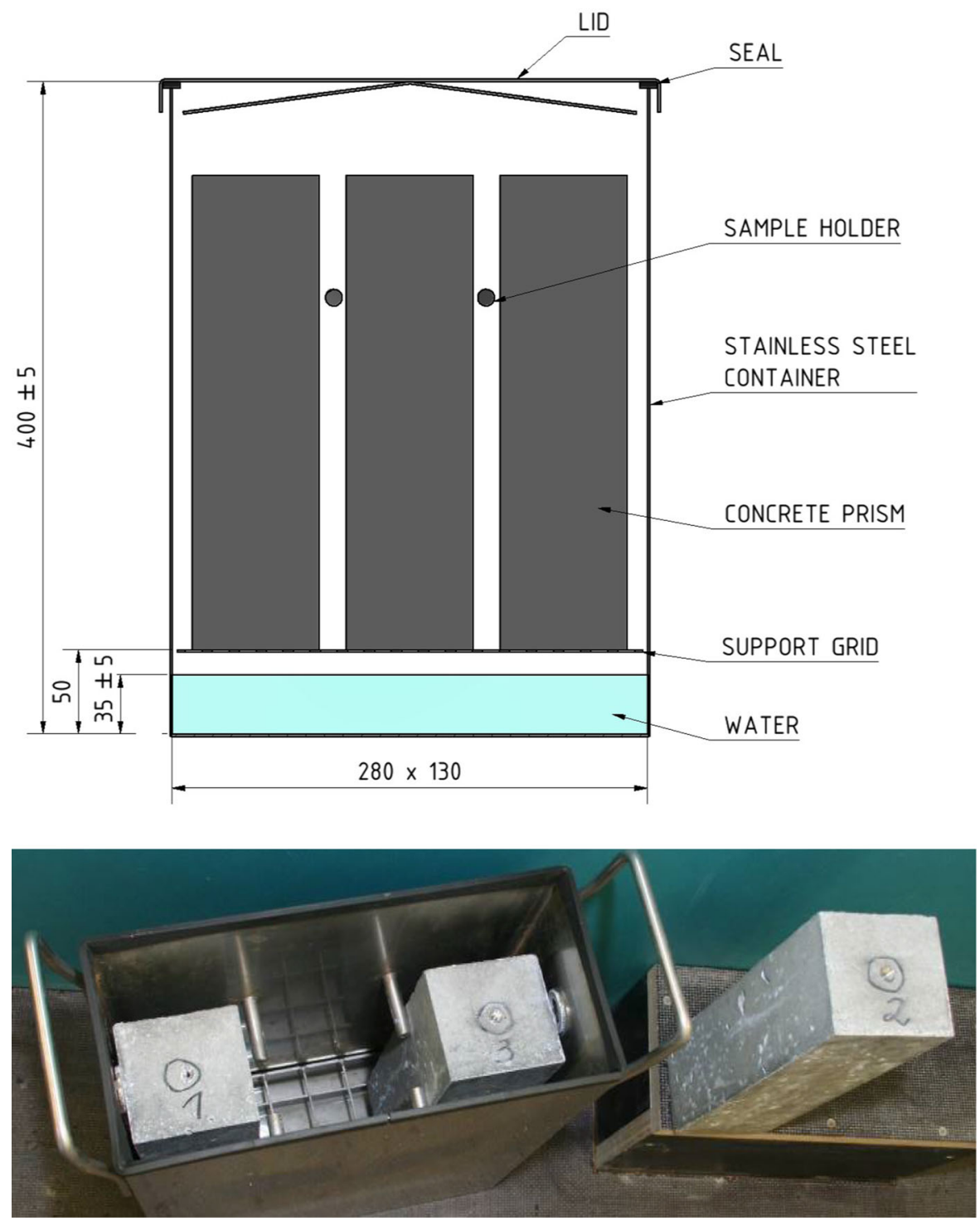

Fig. 4 Sealable containers suitable for the AAR-12 for storing concrete prisms (dimensions in $\mathrm{mm}$ ) 
5 Application 1: AAR-12.1: method for determination of critical binder combination to enable the use of reactive aggregate in nonreactive concrete

The task described below is to investigate whether a specific, reactive aggregate product may still be regularly used up to a certain alkali level, provided that additional requirements are set for the cement/ binder combination. This application assumes that the aggregate has been classified as reactive and that information on its content of (potentially) reactive minerals, degree of reactivity or alkali threshold level has been established. Use of this application for compliance assessment (with regional regulations) also assumes that both aggregates and cement/binder within the region are subject to routine auditing and compliance assessment. This application may be used to establish a minimum SCM level, maximum alkali level, or combinations of SCM and alkali levels for which the aggregate may safely be used. This application requires an expansion acceptance limit to be established for assessing the SCM (or alkali/SCM) limit.

\subsection{Materials}

\subsubsection{Sodium hydroxide}

Sodium hydroxide of at least technical grade (not less than $98 \%$ sodium hydroxide by mass).

Note 9 Caution: Care should be taken when handling this chemical (and concrete containing it), and suitable protective clothing should be worn.

\subsubsection{Portland or composite cement, additions}

A Portland cement (EN197-1 [18] CEM I or ASTM C150 [19] Type I-V or similar) may be chosen (for alternatives, see below); its alkali contribution to the test mix should be as close as possible to the intended alkali level(s) at which the aggregate shall be tested. If necessary, sodium hydroxide shall be added to the concrete mix water to increase the alkali content of the mix to the intended levels. It is recommended to design the test series in steps of approximately $0.5 \mathrm{~kg}$ sodium oxide equivalent per cubic meter (see Sect. 8.2).
SCMs of a specific origin and/or properties may be chosen to be included in the mix design at the minimum content of the intended content range. Depending on the intended validity of the test and the variety of the properties or source of the SCM constituent, it may be necessary to test more than one sample of the SCM. The alkali content of the SCM must be determined within $\pm 0.01 \%$.

Composite cement containing SCM constituents and a declared range of composition may be chosen. The maximum clinker content and the alkali contribution of the cement clinker must be declared or otherwise determined. The cement clinker alkali content and-if applicable-alkali boosting (see below) shall amount to the maximum clinker (and admixtures) alkali amount for which the test shall be valid. The minimum content of the SCM constituent must be declared as well as its origin. The SCM content in the cement sample must be declared within $\pm 1 \%$ and the SCM's alkali content within \pm $0.01 \%$. Depending on the intended validity of the test and the variety of the properties or source of the SCM constituent, it may be necessary to test more than one cement sample.

If necessary, sodium hydroxide shall be added to the concrete mix water to increase the alkali content of the binder to the desired declaration level for the aggregate or cement clinker level. The alkali boosting level shall encompass to potential variations in the alkali contribution from the binder constituents (see Notes 9, 10, and 11).

Note $10 \quad \mathrm{Na}_{2} \mathrm{O}$ equivalent is defined as $\left(\% \mathrm{Na}_{2}\right.$ $\mathrm{O}+0.658 \% \quad \mathrm{~K}_{2} \mathrm{O}$ ). There is evidence that adding $\mathrm{NaOH}$ does not always have the same effect on the concrete pore solution as using cement manufactured with an equivalent total alkali content. Consequently, the use of cement with the required high alkali content is preferred to the addition of sodium hydroxide (alkali boosting). The maximum level of alkali boosting considered to adequately represent alkali contribution from the concrete constituents is still subject to research.

Note 11 The effective alkali contribution of cement clinker is expected to be somewhat lower than that of its total alkali content. Hence, it is believed that alkali boosting slightly overestimates the effect of a similar alkali contribution from additional cement content. This motivates the use of alkali boosting instead of 
increasing the cement content, as the latter will impact $\mathrm{w} / \mathrm{b}$ and, hence, the internal moisture conditions and expansion characteristics. On the other hand, the effective alkali content of alkalis contained in pozzolanic materials is normally much lower than their total alkali content, and so alkali boosting to compensate for alkali variations of such materials may overestimate the real influence of such variations and discredit the beneficial effect of their use.

\subsubsection{Aggregates}

The aggregate combination shall consist of one or more of the following:

(i) Fine and coarse test aggregates;

(ii) Fine and coarse test aggregates of fixed grading;

(iii) Fine test aggregate combined with a nonreactive coarse aggregate;

(iv) Coarse test aggregate combined with a nonreactive fine aggregate.

The test aggregate is to be understood as "an assumed reactive" test candidate, subject to ASR susceptibility assessment. The non-reactive fine or coarse aggregate shall have expansions in the RILEM AAR-2 mortar-bar test of less than $0.05 \%$ at 14 days (Note 12).

Note 12 This critical AAR-2 expansion limit is deliberately more restrictive than is generally applied in order to ensure that the non-reactive aggregate has minimal effect on the expansion results.

Aggregate proportions are determined according to the most-susceptible aggregate combination intended for use (see Sect. 3): When planning the mix design for the combinations (i) and (iv) above, the aggregates shall be combined in the following proportions (calculated on volume basis), and the tested aggregate fractions will be considered generally validated [Notes 13, 14 and 15 and assuming that all fractions are equally reactive in combination (i)] if:

Fine aggregate - maximum $40 \%(0 / 4 \mathrm{~mm})$

Coarse aggregate - minimum $60 \%(4 / 22.4 \mathrm{~mm})$
Note 13 The coarse and fine aggregates should have a controlled content of fines, for example see criteria in EN 12620 [20] or ASTM C33 [21].

When planning the mix design for the combination (ii) above, the combination will be considered generally validated for the fixed grading only.

When planning the mix design for the combination (iii) above, the (test;) aggregate fraction may be maximized within the concrete mix design requirements (Sect. 5.2 and Notes 13, 14 and 15), and the tested aggregate fraction will be considered generally validated for fraction amounts up to this maximized content.

Note 14 A combined aggregate grading curve range found to ensure a concrete matrix suited for production of workable and stable concrete for many aggregate types is given in Table 5 of Sect. 8.3.

Note 15 If it is desired to maximise the proportion of potentially reactive material in the test concrete, the highest amount of the appropriate aggregate fraction should be chosen from Table 5, for example, $45 \%$ of the total aggregate for a potentially reactive $0 / 2 \mathrm{~mm}$ sand, $55 \%$ for a potentially reactive $0 / 4 \mathrm{~mm}$ sand or $60 \%$ for a potentially reactive coarse aggregate. If there is doubt with respect to which fraction is to be considered as the most potentially reactive, it is recommended to test the possible "worst case" combinations of the fractions in question. It may be necessary to investigate which of the fractions (fines/coarse) is the worst one, since this depends on the aggregate type.

\subsubsection{Sodium chloride solution}

$3 \%$ of sodium chloride solution (30 g sodium chloride, technical grade $\geq 99,0 \%$, in $970 \mathrm{~g}$ potable water).

$10 \%$ of sodium chloride solution (100 g sodium chloride, technical grade $\geq 99,0 \%$, in $900 \mathrm{~g}$ potable water).

\subsection{Concrete mix design and preparation}

See also Sect. 8.4.

The concrete mix design is determined by the specific range of cement/binder combination covered 
by the objectives of testing, but the w/b shall be fixed. General advice is given in Table 1.

It is important that the concrete mix is sufficiently workable to enable good compaction. Ideally, the slump value should be in the range of $100-130 \mathrm{~mm}$, with recommended limits of $80 \mathrm{~mm}$ (lowest) and $150 \mathrm{~mm}$ (highest). Concrete with slump value $\leq 100$ $\mathrm{mm}$ should be vibrated. Concrete with a slump value $>100 \mathrm{~mm}$ should be compacted manually by rodding.

Note 16 Admixtures: (1) If the maximum air content requirement is difficult to fulfil, a de-foaming agent should be applied. However, this must not contribute significant alkalis to the concrete. If it does, this must be included in the calculation of the added sodium hydroxide (see Sect. 8.2). (2) Limited amounts of superplasticizer may be used-and shall be used to ensure dispersion if the mix design includes silica fume.

The mixing procedure is: first pre-wet the fine aggregate for a period of at least $16 \mathrm{~h}$ to a total water content of $5 \pm 2 \%$. Then proceed as in the sequence shown in Table 2 (necessary mixing time for good quality mixing may vary, depending on the equipment and material properties).

Before mixing the concrete, the mixer should be wiped out with wet cotton cloth to humidify the mixer.

Note 17 Worked examples of mix design calculation are given in Sect. 8.4.

Table 1 General concrete mix design
Note 18 The free (or effective) water is the water available for hydration of cement and for the workability of the fresh concrete. The total water added to the mix is the free water plus water absorbed by the aggregate to bring it to a saturated surface dry condition.

Note 19 Summary on workability: it is important that the mix is sufficiently workable to enable good compaction. Ideally, the slump value should be in the range of 100-130 mm, with recommended limits of $80 \mathrm{~mm}$ (lowest) and $150 \mathrm{~mm}$ (highest). With some flaky aggregates the above mix might not be sufficiently workable. If the slump value of the concrete is too low, a superplasticizer with low alkali content (not one combined with an air-entraining agent) should be used. In this case the (small) amount of alkali contributed by the superplasticizer should be taken into account in calculating the amount of additional sodium hydroxide to be added (see Sect. 8.2). The free water in the amount of superplasticizer expected to be added should also be considered in calculating the total content of water to be added (see Sect. 8.4). The slump value should not exceed $150 \mathrm{~mm}$ (even when using some superplasticizer).

\subsection{Casting test specimens}

If using mould oil as a release agent when casting the specimens, avoid the use of too much oil and ensure

\begin{tabular}{ll}
\hline Total cement and binder content & Approximately $440 \mathrm{~kg} / \mathrm{m}^{3}$-or see Sect. 3 \\
Free (effective) water content & Approximately $210 \mathrm{~kg} / \mathrm{m}^{3}$-or see Sect. 3 \\
Water/binder ratio (effective) & 0.48 -Fixed (by mass) \\
Coarse aggregate & $60 \%$ by volume (or as specified in 5.1.3) \\
Fine aggregate & $40 \%$ by volume (or as specified in 5.1.3) \\
Air content & $\leq 3 \%$ \\
\hline
\end{tabular}

Table 2 Mixing sequence and periods

\begin{tabular}{lll}
\hline Add materials in sequence: & Add materials (seconds from start of mixing) & Total mixing time (seconds) \\
\hline Sand + Coarse aggregate & 0 & 60 \\
$1 / 2$ water + added $\mathrm{NaOH}$ (see Sect. 8.2) & $60-120$ & $120-180$ \\
Pause & $120-180$ & $180-240$ \\
Cement $+1 / 2$ water $(+$ plasticizer if needed) & $180-240$ & $300-420$ \\
\hline
\end{tabular}


that the reference studs are kept dry and not coated with oil.

Cast three test prisms from each concrete mix to be investigated, compacting the concrete into the moulds in two layers of equal depth using mechanical vibration or rodding, as appropriate (see Sect. 4.7). Compact sufficiently but avoid excessive vibration, which may cause segregation. Strike off and finish the top surface of the prisms with a minimum of effort; do not continue finishing once a flat and even surface is produced.

Cure at $20 \pm 2{ }^{\circ} \mathrm{C}$ in relative humidity of not less than $90 \%$ under moist covers for $24 \pm 2 \mathrm{~h}$.

Note 20 In tropical countries, higher curing temperatures sometimes apply. It is important to note that this may change the pore size distribution and later moisture exchange mechanics and, hence, influence some of the conditions having impact on the expansion (see Sect. 8.1).

\subsection{Storage and measurement}

\subsubsection{Initial storage conditions and initial measurement procedure}

After demoulding, identify and indelibly mark each concrete prism, including an arrow pointing towards the "top" of each prism for the purpose of using a consistent orientation for length measurements. Then examine the prism and record any defects.

Note 21 De-mould and measure the prisms in sets of three. Do not de-mould more than three prisms at one time and attempt to measure consecutively; this will result in excessive drying, which could affect the expansive behaviour.
Immediately measure the initial length $(l)$ of each prism to the nearest $1 \mathrm{~mm}$ using a steel rule.

Afterwards start the pre-storage until the age of 28 days (see Table 3):

1. Verify that there is $35 \pm 5 \mathrm{~mm}$ of water in the container and place the prisms inside. Each container holds a maximum of either three prisms or six prisms. It is important that a full set of specimens (i.e. either 3 or 6 ) are in the container. If fewer test specimens are needed, the number should be made up with "dummy" specimens. Seal the lid and store the container at $20 \pm 2{ }^{\circ} \mathrm{C}$ for 6 days. Store the containers in a high relative humidity chamber (e.g. the curing chamber) if possible; otherwise, the measurement room will be an acceptable storage location

2. At an age of 7 days, remove the prisms from the container and store them for 14 days at $20 \pm 2{ }^{\circ} \mathrm{C}$ and relative humidity of $65 \pm 5 \%$ on racks that permit free circulation of air around all surfaces of the prisms, and with at least $50 \mathrm{~mm}$ clearance on all sides of each prism.

3. At an age of 21 days, re-store the prisms in its container with a water level of $35 \pm 5 \mathrm{~mm}$ and seal the lid. Store the container for 6 days in the $60 \pm 2{ }^{\circ} \mathrm{C}$ reactor. Ensure that the reactor contains an appropriate level of water.

4. At an age of 27 days remove the container from the reactor and ensure the cover is securely in place. DO NOT OPEN the containers. Cool the specimens to the same temperature as the measurement room by storing the container at $20 \pm 2{ }^{\circ} \mathrm{C}$ for $24 \pm 2 \mathrm{~h}$. Store the container in a high relative humidity chamber if possible; otherwise, the measurement room will be an acceptable storage location.

Table 3 Storage conditions prior to initial measurement at 28 days after casting

\begin{tabular}{llll}
\hline Step & $\begin{array}{l}\text { Age of concrete } \\
\text { (days from casting) }\end{array}$ & Duration & Storage condition \\
\hline 0 & $0-1$ & $24 \pm 2 \mathrm{~h}$ & $20 \pm 2{ }^{\circ} \mathrm{C}, \geq 90 \% \mathrm{RH}$, in moulds \\
1 & $1-7$ & 6 days & $20 \pm 2{ }^{\circ} \mathrm{C}$ in sealed test containers \\
2 & $7-21$ & 14 days & $20 \pm 2{ }^{\circ} \mathrm{C}, 65 \pm 5 \%$ RH on drying racks \\
3 & $21-27$ & 6 days & $60 \pm 2{ }^{\circ} \mathrm{C}$ above water in sealed test containers in reactor \\
4 & $27-28$ & $24 \pm 2 \mathrm{~h}$ & $20 \pm 2{ }^{\circ} \mathrm{C}$ in sealed test containers \\
\hline
\end{tabular}


Note 22 The pre-storage simulates real conditions to which concrete is exposed in practice. Therefore, the prisms are stored in a humid environment first and afterwards in a dry climate with a relative humidity of $65 \pm 5 \%$. A relative humidity of $50 \%$ may also be used, if more appropriate. During the first storage in the $60 \pm 2{ }^{\circ} \mathrm{C}$ reactor from the age of 21 days, the concrete again absorbs water. This reduces the hygric parts of the expansion during the test after the zero measurement at the age of 28 days.

At the age of 28 days, clean the reference studs and take an initial reading on the comparator $\left(C_{0}\right)$ using the Invar ${ }^{\circledR}$ rod to calibrate the length of the measuring apparatus (see Sect. 5.4.3). For each measurement, keep the Invar ${ }^{\circledR}$ rod and the prism in the same position (top and bottom in position, the same rod surface and same prism face towards the operator). Ensure the prism is well-located in the measuring apparatus before making any readings. Weigh the prisms to the nearest $1 \mathrm{~g}\left(W_{0}\right)$. Initial measurements are to be made at a temperature of $20 \pm 2{ }^{\circ} \mathrm{C}$ (see also Sect. 8.1 for tropical countries).

\subsubsection{Storage conditions during subsequent test period}

From an age of 28 days the prisms undergo the alternating storage, which is repeated at an interval of 14 days for a total of ten times (see Table 4). Three prisms have to be tested for each test solution.

1. Place the prisms in a dryer with an air supply for 5 days at $60 \pm 5^{\circ} \mathrm{C}$.
2. After 5 days, remove the prisms from the dryer and cool them off in a closed box for $4 \pm 1 \mathrm{~h}$ at $20 \pm 2{ }^{\circ} \mathrm{C}$ and a relative humidity of $65 \pm 5 \%$. After this, store the prisms in a horizontal position on the supports in sealed containers with test solution (see Sect. 5.1.4) for $48 \pm 2 \mathrm{~h}$ at $20 \pm 2{ }^{\circ} \mathrm{C}$. The containers are to be filled with the test solution in a way that the prisms are fully covered. The volume ratio of prisms and test solution is $1: 1.6$. The test solution should be replaced for each exposure cycle. Sodium chloride solutions of $10 \%$ and $3 \%$ are used (see Sect. 5.1.4). Diluted runway de-icing solutions may also be taken as test solution.

3. After storing the prisms in the test solution for 2 days, place the prisms in containers with $35 \pm 5 \mathrm{~mm}$ of water at the bottom, when the surplus solution has dripped off the surface. Check the water level in the container, adjust water content if necessary and replace the container cover. If contaminated, remove water and clean the container, pour a new portion of water and replace the container cover. Place the sealed container in the $60 \pm 2{ }^{\circ} \mathrm{C}$ reactor for 6 days. Check the water level in the reactor and add water if necessary.

4. After 6 days, remove the sealed containers from the reactor and ensure the cover is securely in place. DO NOT OPEN the containers. Cool the specimens to the same temperature as the measurement room by storing the container at $20 \pm 2{ }^{\circ} \mathrm{C}$ for $24 \pm 2 \mathrm{~h}$. Store the container in a high relative humidity chamber if possible;

Table 4 Storage conditions during test period

\begin{tabular}{llll}
\hline Step & $\begin{array}{l}\text { Test period (days from most recent } \\
\text { measurement) }\end{array}$ & Duration & Storage condition \\
\hline 1 & $0-5$ & 5 days & $60 \pm 5{ }^{\circ} \mathrm{C}$ in dryer \\
2 & 5 & $4 \pm 1 \mathrm{~h}$ & $20 \pm 2{ }^{\circ} \mathrm{C}, 65 \pm 5 \% \mathrm{RH}$ in closed container \\
& $5-7$ & $48 \pm 2 \mathrm{~h}$ & $20 \pm 2{ }^{\circ} \mathrm{C}$ fully immersed in test solution in sealed container (see \\
& & & Sect. 5.1.4) \\
3 & $7-13$ & 6 days & $60 \pm 2{ }^{\circ} \mathrm{C}$ above water in sealed test containers in reactor \\
4 & $13-14$ & $24 \pm 2 \mathrm{~h}$ & $20 \pm 2{ }^{\circ} \mathrm{C}$ in sealed test containers \\
5 & 14 & - & $\begin{array}{l}\text { Measure prisms } \\
\text { Return to step 1 }\end{array}$ \\
& & & Repeat the cycle of steps 1-5 ten times \\
\hline
\end{tabular}


otherwise, the measurement room will be an acceptable storage location.

5. After $24 \pm 2 \mathrm{~h}$ in storage at $20 \pm 2{ }^{\circ} \mathrm{C}$, measure the length of the prism and weigh the prisms according to Sect. 5.4.3

After the length and the weight of the prisms are measured, continue with the next cycle of the alternating storage by following the steps 1-5.

\subsubsection{Procedures for length and weight measurements}

After storage at $20 \pm 2{ }^{\circ} \mathrm{C}$ for $24 \pm 2 \mathrm{~h}$, make an initial reading on the comparator using the Invar ${ }^{\circledR} \operatorname{rod}$ to calibrate the length of the measurement apparatus.

Follow the steps $1-11$, to measure the prisms in each container. Each prism measurement should take no more than $3 \mathrm{~min}$ to avoid excessive drying. Always measure the prisms in the same sequence as in the reference measurements.

1. Take the first prism from the container and replace the container cover immediately.

2. Clean the reference studs carefully and place the prism in the apparatus.

3. Measure the prism length using the comparator ( $C_{\mathrm{t}}$ where $t=$ time in weeks). For each measurement, keep the prism in the same position (top and bottom in position, the same prism face towards the operator, arrow pointing in the same direction). Ensure the prism is well-located in the measuring apparatus before making any readings.

4. Remove any excess of moisture and weigh the prism ( $W_{t}$ where $t=$ time in weeks) to the nearest $1 \mathrm{~g}$.

5. Examine the prism and note and record any cracking, gel exudations, warping or other features.

6. Return the prism to its container.

7. Remove the next prism from the container and replace the container cover immediately.

8. Repeat steps 2 through 6 also for the second and third prism from the container. If six prisms are stored in one container follow the steps 2 through 6 for all six prisms.

9. Once all the prisms from one container have been measured, check the reading of the Invar ${ }^{\circledR}$ rod. If the difference is more than $0.003 \mathrm{~mm}$ from the first measurement, measure all prisms for this container again, following steps 1 through 8 .

10. After checking the reading of the Invar ${ }^{\circledR} \operatorname{rod}$, examine the prisms and note and report any cracking, gel exudations, warping or other features.

11. Place the prisms in a dryer with an air supply for 5 days at $60 \pm 5{ }^{\circ} \mathrm{C}$ (see Sect. 5.4.2, step 1).

Repeat steps 1-11 for all containers.

Note 23 If the amount of water in the container exceeds the initial level of $35 \pm 5 \mathrm{~mm}$ or there are signs that substantial moisture has been lost, this might indicate that the lid was not sealed tight, allowing moisture to enter the container or evaporate from the container. However, some water will also be absorbed by the concrete prisms. If the lid is not sealed sufficiently tight, the prims must be placed in a new, defect-free container for continuation of the test. If the water level in the container at any time reaches the prisms or the water at the bottom of the container totally dries out, the measurements should be discarded.

\subsubsection{Measurement timetable}

Measure the prisms $\left(C_{\mathrm{t}}\right.$ and $\left.W_{t}\right)$ according to the detailed procedure in Sect. 5.4.3 after each 14-day cycle of the storage conditions detailed in Sect. 5.4.2. Continue until the specimens have been subjected to a total of 10 cycles.

\subsection{Expression and reporting results}

\subsubsection{Calculations}

For each period of measurement, calculate the change in length and weight for each prism from the difference between the reference comparator or weight measurement $\left(C_{0}, W_{0}\right)$ and the comparator or weight measurement after that period $\left(C_{t}, W_{t}\right)$. Calculate each length change as a percentage of the initial length $(l)$ of the corresponding prism to the nearest $0.001 \%$ and the weight change as a percentage of the reference weight $\left(W_{0}\right)$ of the corresponding prism to the nearest $0.01 \%$.

For example, at 20 weeks the percentage length change $\Delta E_{20}[\%]$ of a prism is given by 
$\Delta E_{20}=\frac{C_{20}-C_{0}}{l} \times 100$

where $C_{20}$ is the comparator measurement after 20 weeks, $C_{0}$ is the reference comparator measurement of the prism and $l$ is the initial length of that prism (in $\mathrm{mm}$ ).

The corresponding percentage weight change $\Delta W_{20}$ of a prism is given by:

$\Delta W_{20}=\frac{W_{20}-W_{0}}{W_{0}} \times 100$

where $W_{20}$ is the weight measurement after 20 weeks and $W_{\mathrm{o}}$ is the reference weight of the prism.

For each measurement age, also calculate the mean length change of the three prisms to the nearest $0.001 \%$ and the mean weight change to the nearest $0.01 \%$.

For example, at 20 weeks the mean percentage length change $\mathrm{mE}_{20}$ of the three test prisms is given by:

$m E_{20}=\frac{\Delta E_{20 / 1}+\Delta E_{20 / 2}+\Delta E_{20 / 3}}{3}$

\subsubsection{Reporting}

5.5.2.1 General For each prism and each measurement age, report the length change as a percentage of the initial length $(l)$ of the corresponding prism to the nearest $0.001 \%$ and report the weight change as a percentage of the reference weight $\left(W_{0}\right.$ ' or $W_{0}$ as applicable) of the corresponding prism to the nearest $0.01 \%$.

For each measurement age, report the mean length change of the three prisms to the nearest $0.001 \%$ and the mean weight change to the nearest $0.01 \%$.

Measurement of any weight loss $\left(\Delta W_{t}\right)$ of a prism confirms there is insufficient water present in the system. AAR reactive mixes will not necessarily exhibit expansion if insufficient water is available. If a net weight loss is recorded at the time of executing the last length readings, the measurements relating to these prisms shall be discarded.

Note 24 Re-wetting would not necessarily allow any previous expansive reactions to be reactivated and subsequent results would be unreliable. Experience has shown that weight gain in the test is related to curing conditions; in particular, high humidity early curing can later lead to relatively low weight gain in the test, but results associated with unexpectedly low weight gains or even small weight losses should still be treated with caution.

The measurements shall also be discarded if, at any time during the test period, either no water is left in the bottom of the storage container or the water in the bottom of the storage container has increased and come in contact with the prisms allowing them to absorb water (in which case the extent of leaching of alkalis from the prisms will be increased).

5.5.2.2 Assessment To determine the minimum amount of the SCM addition (at a fixed alkali level) to produce a non-deleterious concrete with the test aggregate, plot the expansion test results against the amount of the SCM addition as shown in Fig. 5. The intersection of the plot and the pre-established acceptance criteria determines the minimum amount of the SCM addition of this combination. If the expansion values of all points in the test series are below the expansion acceptance limit, the valid minimum amount of the SCM addition (at the fixed alkali level) is the lowest one of those tested.

If the investigation comprises more than one level of alkali content from cement clinker + admixtures (including alkali boosting), the test results for each alkali level may be plotted separately, displaying the required SCM content for each alkali level. Alternatively, the results for a fixed SCM content (SCM content is zero in the case of using CEM I (EN 197-1) alone for alkali threshold determination) may be plotted against alkali content as shown in Fig. 6 to determine the critical alkali level of the aggregate with that binder composition.

Note 25 Useful information could be obtained by petrographic examination of the prisms after the completion of the test to confirmer that ASR caused the expansion.

\subsubsection{Additionally report}

- The mix design;

- The aggregate source and composition (incl. reference to reports from petrographic examination and/or other investigations enabling adequate classification, such as supplementary measurements of alkali threshold); 
Fig. 5 Schematic of the procedure for the determination of the minimum content of an SCM constituent

\section{Expansion [\%]}

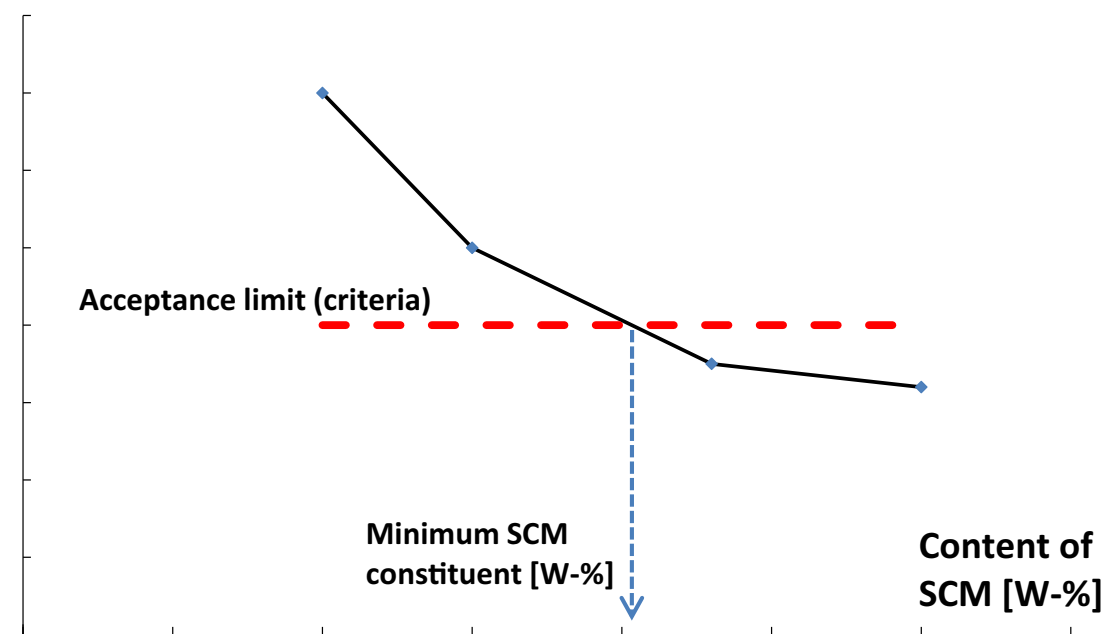

- The cement type, source and clinker alkali content; and for composite cements also include the SCM type, source and content;

- The SCM (if added separately) type, source and alkali content;

- Any superplasticizer additions and any alkali contributed by the superplasticizer;

- Any alkali additions;

- The prism size used;

- The slump of concrete used in the prisms;
- Observations of any cracking, gel exudations, warping or other features;

- Additional factors that may influence the limits of general validity of the testing program findings, with respect to aggregate fractions/-combinations, alkali level, and the type, properties, and origin of cement and SCM additions
Fig. 6 Schematic procedure for the determination of maximum alkali content, from cement clinker and any chemicals including alkali boosting

\section{Expansion [\%]}

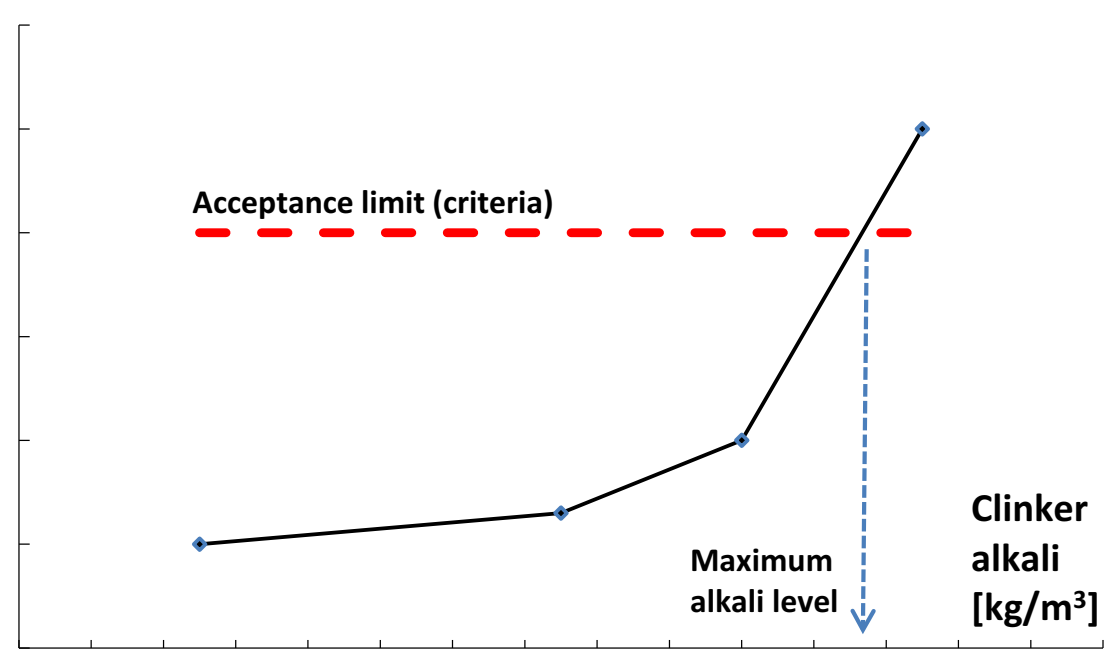




\section{Application 2: AAR-12.2: method for determination of critical alkali level for a specific binder combination together with reactive aggregates in a region}

The task described below is to investigate whether a specific composite cement, or cement plus specific addition, may be regularly used as a mitigating measure in combination with a range of regional/national aggregates up to a certain alkali level, provided that certain properties for the cement/binder are defined and declared by the supplier(s). This application may be used to establish an alkali level that is valid for all reactive aggregates in a region in combination with a specific binder combination; this alkali level may be different than that valid in combination with Portland cement. This application requires an expansion acceptance limit to be established for assessing the (new) alkali limit. The use of this application for compliance control with regional regulations also assumes that both aggregates and cement/binder within the region are subject to routine auditing and compliance assessment. A reference aggregate combination or set of combinations for the region must also be established.

\subsection{Materials}

\subsubsection{Sodium hydroxide}

See Sect. 5.1.1.

\subsubsection{Cement and additions}

See Sect. 5.1.2.

\subsubsection{Aggregates}

The principles and concerns listed in AAR-12.1 (see Sect. 5.1.3) apply, BUT:

The intent of this application is to establish a generic solution within a market area of either composite cement or any cement plus an addition (see Sect. 3). Hence, a generic worst-case aggregate combination and grading within that intended market area should be established. The generic cement/binder solution may comprise any of the following reference aggregate combinations: (i) Non-reactive fine aggregate combined with a reactive coarse aggregate;

(ii) Reactive fine aggregate combined with a nonreactive coarse aggregate;

(iii) Reactive fine aggregate combined with a reactive coarse aggregate.

\subsection{Concrete mix design and preparation}

See Sect. 5.2, but: with exception for the prescribed water/binder ratio, the amounts/ratios of the constituents may be changed for regional practices/standards following mix design needs (e.g. water requirement of the aggregates), however such changes should not be made from test series to test series.

\subsection{Casting test specimens}

See Sect. 5.3.

6.4 Storage and measurement

See Sect. 5.4.

6.5 Expression and reporting results

\subsubsection{Calculations}

See Sect. 5.5.1.

\subsubsection{Reporting}

\subsubsection{General See Sect. 5.5.2.1.}

6.5.2.2 Assessment For the selected type and level of SCMs (used as an addition or incorporated in the cement) and reference aggregate combination being investigated: determine the maximum allowable alkali level (originating from cement clinker and admixtures) to produce a non-deleterious concrete. Plot the expansion test results against the alkali content as shown in Fig. 6. The intersection of the plot and the pre-established acceptance criteria determines the maximum alkali level of this combination. If the expansion values of all points of the test series are below the expansion acceptance limit, the valid alkali level is the highest level tested. 
If the investigation comprises more than one cement/binder and aggregate combination, the test results for each combination shall be plotted separately, determining the maximum alkali content for each combination.

\subsubsection{Additionally report See Sect. 5.5.2.3.}

\section{Application 3: AAR-12.3: method}

for determination the asr-resistance of a specific concrete mix

The task described below is to investigate whether a specific concrete mix may have a sufficient ASRresistance.

\subsection{Materials}

\subsubsection{Sodium hydroxide}

See Sect. 5.1.1.

\subsubsection{Cement and additions}

See Sect. 5.1.2.

\subsubsection{Aggregates}

The aggregate combination shall be used as planned in the concrete mix design.

\subsection{Concrete mix design and preparation}

See Sect. 5.2, but, the concrete mixture shall be the planned job mix.

Note 26 The majority range of $\mathrm{w} / \mathrm{b}$ is between 0.40 and 0.45 .

\subsection{Casting text specimens}

See Sect. 5.3.

\subsection{Storage and measurement}

See Sect. 5.4.
7.5 Expression and reporting results

\subsubsection{Calculations}

See Sect. 5.5.1.

\subsubsection{Reporting}

\subsubsection{General See Sect. 5.5.2.1.}

7.5.2.2 Assessment Examples are given in [7, 8].

7.5.2.3 Additionally report See Sect. 5.5.2.3.

\section{Annex A: Information regarding apparatus, casting, curing and specimen storage}

(Comments relate to clauses as numbered in the method).

\subsection{Casting, curing and measuring environment} (see Sect. 4.8)

Curing at a standard temperature is necessary to obtain reproducible results. In countries with hot climates, however, it may occasionally be necessary to allow the casting, curing and measurement to be carried out in a room maintained at a temperature higher than the preferred $20{ }^{\circ} \mathrm{C}$, up to a maximum of $27 \pm 2{ }^{\circ} \mathrm{C}$ and not less than $65 \pm 5 \% \mathrm{RH}$.

A controlled temperature of $20{ }^{\circ} \mathrm{C}$ is preferred and strongly recommended for this stage of the test. Whatever standard temperature might be adopted $\left(20{ }^{\circ} \mathrm{C}\right.$ or another value up to $27{ }^{\circ} \mathrm{C}$ ) for a particular test, it is essential that the same procedure and the same temperature are used consistently throughout the test. However, use of a temperature other than $20{ }^{\circ} \mathrm{C}$ will necessitate reconsideration of the expansion limits.

8.2 Calculation of sodium hydroxide to be added to the mixing water (see Sect. 5.1.2)

In the following, two examples are given showing how to determine the amount of sodium hydroxide $(\mathrm{NaOH})$ to be added to the mixing water to increase the alkali content up to the intended level. 
Example 1 Performance testing of a CEM II/A-V fly ash cement with clinker alkali content $1.0 \%$. Two mixtures will be made with intended total alkali contents of 5.00 (A) and 5.50 (B) $\mathrm{kg} \mathrm{Na}_{2} \mathrm{O}_{\text {eq. }}$. per $\mathrm{m}^{3}$ of concrete, respectively. The alkali content of the fly ash is not included in the calculations.

\section{Mixture A}

Cement content per $\mathrm{m}^{3}$ of concrete $=440 \mathrm{~kg}$

Assumed content of superplasticizer per $\mathrm{m}^{3}$ of concrete $=2.0 \mathrm{~kg}$

Intended total alkali content; $\mathrm{Na}_{2} \mathrm{O}_{\text {eq. }}$ per $\mathrm{m}^{3}$ of concrete $=5.000 \mathrm{~kg}$

Amount of $\mathrm{Na}_{2} \mathrm{O}_{\text {eq. }}$ in the cement clinker $(1.0 \%)=$ $440 \times 0.01=4.400 \mathrm{~kg}$

Amount of $\mathrm{Na}_{2} \mathrm{O}_{\text {eq. }}$ in the superplasticizer $(1.0 \%)=$ $2 \times 0.01=0.020 \mathrm{~kg}$

Amount of $\mathrm{Na}_{2} \mathrm{O}_{\text {eq. }}$ to be added per $\mathrm{m}^{3}$ of concrete $=$ $5.000-4.400-0.020=0.580 \mathrm{~kg}$

The conversion factor $\mathrm{Na}_{2} \mathrm{O}_{\text {eq }}$ to $\mathrm{NaOH}$ is 1.291 .

Amount of $\mathrm{NaOH}$ required (to be added to the mixing water $)=0.580 \times 1.291=0.749 \mathrm{~kg}$

The purity of the technical grade $\mathrm{NaOH}$ to be used is $98 \%$. Amount of technical grade $\mathrm{NaOH}$ required (to be added and mixed together with the first half of the mixing water $)=(0.749 / 98) \times 100=0.764 \mathrm{~kg}$

\section{Mixture B}

Amount of $\mathrm{Na}_{2} \mathrm{O}_{\text {eq. }}$ to be added per $\mathrm{m}^{3}$ of concrete $=$ $5.500-4.400-0.020=1.080 \mathrm{~kg}$

The conversion factor $\mathrm{Na}_{2} \mathrm{O}_{\text {eq. }}$ to $\mathrm{NaOH}$ is 1.291 . Amount of $\mathrm{NaOH}$ required (to be added to the mixing water $)=1.080 \times 1.291=1.394 \mathrm{~kg}$

The purity of the technical grade $\mathrm{NaOH}$ to be used is $98 \%$. Amount of technical grade $\mathrm{NaOH}$ required (to be added and mixed together with the first half of the mixing water $)=(1.394 / 98) \times 100=1.423 \mathrm{~kg}$

Example 2 Performance testing of a binder composed of $400 \mathrm{~kg} / \mathrm{m}^{3}$ CEM I cement (alkali content $0.9 \%$ ) and $20 \mathrm{~kg} / \mathrm{m}^{3}$ (5\% of the cement) silica fume (alkali content $0.68 \%$ ). One mixture will be made with intended total alkali content $4.50 \mathrm{~kg} \mathrm{Na}_{2} \mathrm{O}_{\text {eq. }}$ per $\mathrm{m}^{3}$ of concrete. The alkali content of the silica fume is not included in the calculations.
Cement content per $\mathrm{m}^{3}$ of concrete $=400 \mathrm{~kg}$

Assumed content of superplasticizer per $\mathrm{m}^{3}$ of concrete $=4.0 \mathrm{~kg}$

Intended total alkali content; $\mathrm{Na}_{2} \mathrm{O}_{\text {eq. }}$ per $\mathrm{m}^{3}$ of concrete $=4.500 \mathrm{~kg}$

Amount of $\mathrm{Na}_{2} \mathrm{O}_{\text {eq. }}$ in the cement clinker $(0.90 \%)=$ $400 \times 0.009=3.600 \mathrm{~kg}$

Amount of $\mathrm{Na}_{2} \mathrm{O}_{\text {eq. }}$ in the superplasticizer $(1.0 \%)=$ $4 \times 0.01=0.040 \mathrm{~kg}$

Amount of $\mathrm{Na}_{2} \mathrm{O}_{\text {eq. }}$ to be added per $\mathrm{m}^{3}$ of concrete $=$ $4.500-3.600-0.040=0.860 \mathrm{~kg}$

The conversion factor $\mathrm{Na}_{2} \mathrm{O}_{\text {eq }}$ to $\mathrm{NaOH}$ is 1.291 . Amount of $\mathrm{NaOH}$ required (to be added to the mixing water $)=0.860 \times 1.291=1.110 \mathrm{~kg}$

The purity of the technical grade $\mathrm{NaOH}$ to be used is $98 \%$. Amount of technical grade $\mathrm{NaOH}$ required (to be added and mixed together with the first half of the mixing water $)=(1.110 / 98) \times 100=1.133 \mathrm{~kg}$

\subsection{Aggregates: standard aggregate materials test (see Sect. 5.1.3)}

The aggregate fractions should be combined in mass proportion calculated on a saturated surface dry basis according to Table 5 given below which gives the recommended aggregate grading curve range to achieve a matrix suited for production of workable and stable concrete. To meet these requirements, it is necessary to know the particle size distribution curve of each aggregate.

Note 28 Gaps between two fractions should be avoided. For example, sand 0/2 (2-0 mm) should not be tested with an aggregate $8 / 16(16-8 \mathrm{~mm})$. A general combination with focus on a high amount of the coarse aggregate fraction is given in Table 6.

Note 29 With some reactive aggregates it has been found that specific relative proportions of reactive constituents in the aggregate lead to a maximum expansion. This proportion is called the 'pessimum' content, and the relationship between expansion and content of reactive constituents is called the 'pessimum behaviour' of the reactive aggregate. 
Table 5 Recommended aggregate grading curve range

\begin{tabular}{ll}
\hline Aperture size $(\mathrm{mm})$ & $\begin{array}{l}\text { Percentage by mass } \\
\text { passing the test sieve }\end{array}$ \\
\hline 22.4 & 100 \\
16.0 & $75-95$ \\
8.0 & $45-70$ \\
4.0 & $40-55$ \\
2.0 & $25-45$ \\
1.0 & $20-35$ \\
0.5 & $10-25$ \\
0.25 & $4-12$ \\
0.125 & $1-8$ \\
\hline
\end{tabular}

${ }^{\mathrm{a}}$ The range is selected to accommodate both crushed and uncrushed aggregate

Table 6 General concrete mix design

\begin{tabular}{ll}
\hline Cement content & $440 \mathrm{~kg} / \mathrm{m}^{3}$ \\
Free (effective) water content & $210 \mathrm{~kg} / \mathrm{m}^{3}$ \\
Water/binder ratio (effective) & 0.48 \\
Coarse aggregate & $60 \%$ by volume \\
Fine aggregate & $40 \%$ by volume \\
Air content & $<3 \%$ \\
\hline
\end{tabular}

8.4 Concrete mix design and preparation (see Sect. 5.2)

\subsubsection{Preparation of the aggregates}

Pre-wetted fine aggregates are used to ensure a workable and homogeneous concrete. This shall be done using the following procedure:

Determine the water absorption $\left(\mathrm{WA}_{f}\right)$ and initial water content $\left(W_{i}\right)$ of the fine aggregate according to the standards/methods valid in the place of use. Weigh out a sufficient quantity of the fine aggregate, place it into a tray and add a sufficient amount of water calculated to achieve a water content of $5 \pm 2 \%$. Mix the wetted fine aggregate thoroughly and store in sealed containers for at least $16 \mathrm{~h}$. Measure the final water content $\left(W_{f}\right)$ of the fine aggregate.

The coarse aggregate should be used without prewetting, but the water absorption $\left(\mathrm{WA}_{c}\right)$ and the water content $\left(W_{c}\right)$ should be measured.

The amount of water added to the mix to achieve the prescribed free water content of $210 \mathrm{~kg} / \mathrm{m}^{3}$ is then calculated, taking into account both the water absorption and the measured water content of the fine and coarse aggregates. The water absorptions of most fine aggregates will be less than the intended water content (i.e. $5 \pm 2 \%$ ). For most coarse aggregates, the water content will be lower than their water absorptions. In cases where the water content $(W)$ is higher than the water absorption (WA), the contribution from the aggregate $\left(W_{\text {free }}\right)$ to the free water content of the mix can be calculated as:

Contribution from the aggregate $=[($ measured water content of the aggregate - water absorption of the aggregate)/100] $\times$ [calculated mass of the dry aggregate] or

$$
\begin{aligned}
& W_{\text {free }}=[(W-W A) / 100] \\
& \quad \times[(\text { quantity } \\
& \text { ssd } \\
& \text { of the aggregate }) /(1+W A / 100)]
\end{aligned}
$$

In cases where the water absorption of the aggregate is higher than its water content, the extra water needed $\left(\mathrm{W}_{\text {extra }}\right)$ at the mixing stage, to bring the aggregate to a saturated surface dry state, can be calculated as:

Extra water needed $=[$ (water absorption of the aggregate - measured water content of the aggregate)/ $100] \times$ [calculated mass of the dry aggregate] or

$$
\begin{aligned}
& W_{\text {extra }}=[(\mathrm{WA}-W) / 100] \\
& \quad \times[(\text { quantity } \\
& \text { ssd } \\
& \text { of the aggregate }) /(1+\mathrm{WA} / 100)]
\end{aligned}
$$

\subsubsection{Concrete mix design}

A worked example is presented below, see Tables 7, 8, 9, and 10: Performance testing of a CEM II/A-V fly ash cement, aimed total alkali content $5.50 \mathrm{~kg} \mathrm{Na}{ }_{2} \mathrm{O}_{\text {eq. }}$ per $\mathrm{m}^{3}$ of concrete (see Example 1, Mixture B in Sect. 8.2):

Example of concrete mix design calculations for a mix made with one coarse and one fine aggregate is shown (the calculation is the same for more aggregates).

For the mix design it is necessary to know:

- The water absorption (WA) of each aggregate. The values can be determined according to EN 1097-6 [22], ASTM C127 [23] or ISO 7033 [24];

- The densities on an oven dry $\left(\rho_{\text {rd }}\right)$ and saturated surface dry $\left(\rho_{\text {ssd }}\right)$ basis of all fractions. The values can be determined according to EN 1097-6 [22], ASTM C127 [23] and 128 [25] or ISO 7033 [24]; 
Table 7 Properties of the materials

\begin{tabular}{|c|c|c|c|c|c|}
\hline & $\rho_{\text {rd }}(\mathrm{kg} / \mathrm{L})$ & $\rho_{\text {ssd }}(\mathrm{kg} / \mathrm{L})$ & Density (kg/L) & Water Absorption, WA (\%) & Water Content, W (\%) \\
\hline Coarse aggregate & 2.66 & 2.68 & - & 0.8 & 0.3 \\
\hline Fine aggregate & 2.65 & 2.68 & - & 1.1 & 6.2 \\
\hline Cement & - & - & 3.01 & - & - \\
\hline Water & - & - & 1.00 & - & - \\
\hline Sodium hydroxide & - & - & 2.1 & - & - \\
\hline Superplasticizer & - & - & 1.1 & - & 80 \\
\hline
\end{tabular}

Table 8 Calculation of the concrete mix design-Stage 1

\begin{tabular}{lllll}
\hline & Grading $(\mathrm{mm})$ & Proportion $^{\mathrm{a}}(\%)$ & Quantity $\left(\mathrm{kg} / \mathrm{m}^{3}\right)$ & Volume $\left(\mathrm{L} / \mathrm{m}^{3}\right)^{*}$ \\
\hline Coarse aggregate & $4 / 16$ & 60 & $\mathrm{X}$ & $\mathrm{X} / 2.68$ \\
Fine aggregate & $0 / 4$ & 40 & $4 / 6 \times \mathrm{X}$ & $(4 / 6 \times \mathrm{X}) / 2.68$ \\
Cement & - & - & 440 & $(440 / 3.01)=146$ \\
Water (free) & - & - & 210 & 210 \\
Air (assumed 1.5\%) & - & - & - & 15 \\
Superplasticizer & - & - & 2 & $\sim 2$ \\
Sodium hydroxide & - & - & -1.4 & $\sim 1$ \\
Total & - & - & - & $1000^{* *}$ \\
\hline
\end{tabular}

${ }^{a}$ Weight- $\%=$ volume- $\%$ (same density of the fine and the coarse aggregate)

*Based on $\rho_{\text {ssd__saturated surface dry aggregate }}$

**The aim is to calculate the concrete mix design for making $1 \mathrm{~m}^{3}$ of concrete

- The water content (W) of each aggregate. The values can be determined according to EN 1097-5 [26] or ASTM C566 [27].

Assume that the content of superplasticizer (with density $1.1 \mathrm{~kg} / \mathrm{m}^{3}$ and water content $80 \%$ ) required is $2.0 \mathrm{~kg} / \mathrm{m}^{3}$ and that the amount of technical grade $\mathrm{NaOH}$ (with density $2.1 \mathrm{~kg} / \mathrm{m}^{3}$ ) required is $1.4 \mathrm{~kg} /$ $\mathrm{m}^{3}$ - see example in Sect. 8.2.

The volumetric weight and the air content of the fresh concrete should be measured, according respectively to EN 12350-7 [28]/ASTM C1170 [29] and EN 12350-6 [30]/ASTM C173 [31]/ASTM C231 [32]. The ratio between the theoretical and the measured volumetric weights of the fresh concrete should be $1.000 \pm 0.015$ (which corresponds to $440 \pm 6 \mathrm{~kg}$ of cement per $\mathrm{m}^{3}$ of concrete). This will ensure the correct amount of alkali from the cement in the fresh concrete.
Calculation of the quantity $(X)$ of coarse aggregate (saturated surface dry) in $1 \mathrm{~m}^{3}$ of concrete:

$$
\begin{aligned}
& \text { Aggregate volume }=1000-146-210-15-2-1 \\
& =626 \mathrm{~L} / \mathrm{m}^{3} . \\
& (X / 2.68 \mathrm{~kg} / \mathrm{L})+(4 / 6 \times X) / 2.68 \mathrm{~kg} / \mathrm{L} \\
& \quad=626 \mathrm{~L} / \mathrm{m}^{3} . \\
& X=1007 \mathrm{~kg} / \mathrm{m}^{3} .
\end{aligned}
$$

Calculation of the quantity $(4 / 6 \times X)$ of fine aggregate (saturated surface dry) in $1 \mathrm{~m}^{3}$ of concrete:

$4 / 6 \times X=4 / 6 \times 1007 \mathrm{~kg} / \mathrm{m}^{3}=671 \mathrm{~kg} / \mathrm{m}^{3}$.

The contribution from the fine aggregate $\left(W_{\text {free-f }}\right)$ to the free water content can be calculated according to Eq. 4 
Table 9 Calculation of the concrete mix design-Stage 2

*Based on $\rho_{\text {ssd }}$-saturated surface dry aggregate

\begin{tabular}{llll}
\hline & Grading $(\mathrm{mm})$ & Quantity $\left(\mathrm{kg} / \mathrm{m}^{3}\right)$ & Volume $\left(\mathrm{L} / \mathrm{m}^{3}\right)^{*}$ \\
\hline Coarse aggregate & $4 / 16$ & $1007^{*}$ & $(1007 / 2.68)=376$ \\
Fine aggregate & $0 / 4$ & $671^{*}$ & $(671 / 2.68)=250$ \\
Cement & - & 440 & 146 \\
Water (free) & - & 210 & 210 \\
Air & - & - & 15 \\
Superplasticizer & - & 2 & $\sim 2$ \\
Sodium hydroxide & - & 1.4 & $\sim 1$ \\
Total & - & 2320 & $\sim 1000$ \\
\hline
\end{tabular}

Table 10 Final concrete mix design - quantities to be added to the mix

*Based on $\rho_{\mathrm{ssd}}$ - saturated surface dry aggregate

***Free water content is $2 \mathrm{~kg} / \mathrm{m}^{3} \times 80 /$ $100=1.6 \mathrm{~kg} / \mathrm{m}^{3}(\sim 2 \mathrm{~kg} /$ $\mathrm{m}^{3}$ )

\begin{tabular}{llll}
\hline & Grading $(\mathrm{mm})$ & Quantity $\left(\mathrm{kg} / \mathrm{m}^{3}\right)$ & Quantity $\left(\mathrm{kg} / \mathrm{m}^{3}\right)$ \\
\hline Coarse aggregate & $4 / 16$ & $1007^{*}$ & $1007-5=1002$ \\
Fine aggregate & $0 / 4$ & $671^{*}$ & $671+34=705$ \\
Cement & - & 440 & 440 \\
Water (added) & - & 210 & $210+5-34-2=179$ \\
Air & - & - & - \\
Superplasticizer & - & 2 & $2 * *$ \\
Sodium hydroxide & - & 1.4 & 1.4 \\
Total & - & 2320 & 2329 \\
\hline
\end{tabular}

$$
\begin{aligned}
W_{\text {free }-\mathrm{f}} & =[(6.2-1.1) / 100] \times[(671) /(1+1.1 / 100)] \\
& =33.8 \mathrm{~kg}(\sim 34 \mathrm{~kg}) .
\end{aligned}
$$

The extra water needed $\left(W_{\text {extra-c }}\right)$ at the mixing stage to bring the coarse aggregate to a saturated surface dry state can be calculated according to Eq. 5:

$$
W_{\text {extra }-\mathrm{c}}=[(0.8-0.3) / 100] \times[(1007) /(1+0.8 / 100)]=5.0 \mathrm{~kg}
$$

Example of fresh concrete properties measured:

- Slump $=120 \mathrm{~mm}($ target is $100-130 \mathrm{~mm})$

- Air content $=1.4 \%($ target $<3 \%)$

- Measured volumetric weight $=2323 \mathrm{~kg} / \mathrm{m}^{3}$

- Ratio between the theoretical and measured volumetric weights $=(2329 / 2323)=1.003$ (target is 0.985-1.015). If the ratio is outside the range, the quantity of aggregate should be increased/decreased (without changing the proportion between the different aggregates) to meet the requirement of the weight ratio (0.985-1.015).

\section{Annex B: Examples of implementation of principles in this test procedure}

\subsection{Adoption of a performance test and establishing acceptance limits}

Some of the principles incorporated in this document have been employed in national provisions to enable production of non-ASR-reactive concrete under conditions where/when the aggregates are susceptible to reaction. In doing so, the establishing of acceptance criteria in the sense of expansion limits is a central issue.

Applying accelerated testing conditions requires consideration of the impact of those accelerated conditions on the performance of the materials subjected to testing. Assuming that the testing method has been qualified for the type of aggregates to be investigated (Note 30), the establishment of acceptance criteria may be based on a comparison between observations from field service or field exposure sites and based on a pass/failure compared to test results 
applying the testing method, i.e. detecting a critical expansion value. However, the reactivity of aggregates is not necessarily equally accelerated at fixed testing conditions, compared to their properties under ambient conditions. Implicitly, acceptance criteria may be differentiated depending on the type of aggregate minerals or other properties, underlining the need for adequate field observations.

The same dilemma exists for accelerated testing wih SCMs, but constituents such as slag, fly ash and natural pozzolana are believed to exhibit results during testing conditions applied in the present document that are consistent with their performance in field.

Note 30 Some minerals may have a reaction behaviour that deviates from that of the gross of commercially available aggregates. For instance, high porosity may (for a while;) supress expansion during testing by accommodating reaction products to an extent where the normal relation between expansion test results and field observation with other aggregates is no longer valid. Use of light weight aggregates and aggregates exhibiting pessimum behaviour should be subject to special concern.

Information on examples and/or specifics regarding how principles from performance testing are adopted in various countries is provided below, with different degrees of detail:

\subsection{Norway}

In Norway, performance testing is regularly used within the NS-EN 206 framework of compliance/ approval in order to declare alkali limits for (composite) cement products with a minimum content of specific (source) SCMs, for use with "all aggregates" (Application 10.2 of/1/).

The approval follows after testing with a worst-case reference aggregate. The determined maximum alkali level yields the maximum cement content applicable with all national aggregates. The same provisions may be applied for determining a minimum SCM content with specific aggregates (Application $10.1 \mathrm{of} / 1 /$ ).

In Norway, performance-based (in contrast to concrete composition-specification-based;) regulations were already introduced when the national existence of ASR was verified (NB21, 1996)/2/. Acceptance limits for testing (NB21, 2004) were adopted following an extensive national field survey/
3/. The Norwegian ASR regulations were again revised in 2017/4/based on new knowledge gained in research focusing on comparison laboratory test results with observations from field service and field exposure sites. The test method used for performance testing/5/is quite similar to the test method described in this document; prisms of dimension $100 \times 100 \times 450 \mathrm{~mm}^{3}$ are produced and stored at a temperature of $38{ }^{\circ} \mathrm{C}$ and a relative humidity of $\sim$ $100 \%$. This is achieved using containers holding the three prisms on a grid above water.

\subsubsection{Source of information used in Sect. 9.2}

1. Rønning TF, Wigum BJ, Lindgård J (2021) Recommendation of RILEM TC 258-AAA: RILEM AAR-10: determination of binder combinations for non-reactive mix design using concrete prisms $-38{ }^{\circ} \mathrm{C}$ test method, (in press)

2. Norwegian Concrete Association, Durable concrete containing alkali reactive aggregates, NB21, 1996, pp. 27 (in Norwegian).

3. Lindgård, J. and Wigum, B.J., 2003: Alkali Aggregate Reaction in Concrete-Field experiences. SINTEF report STF22 A02616, 2003, (in Norwegian). pp $127+$ appendices.

4. Norwegian Concrete Association, Durable concrete containing alkali reactive aggregates, NB21, 2017, pp. 35 (in Norwegian). www.betong.net

5. Norwegian Concrete Association, Alkali-aggregate reactions in concrete, Test methods and Requirements to Test Laboratories, NB32, 2005, pp. 39 (in Norwegian). (English version available in 2010). www.betong.net

\subsection{Germany}

In Germany, it is common to use ASR-performancetests to verify a high resistance of concrete mixes against deleterious alkali-silica reaction. Fields of applications are presented in Sects. 9.3.1 to 9.3.5.

\subsubsection{Ordinary reinforced concrete and pre-stressed concrete constructions}

In Germany, in general the "Alkali Guidelines" of the German Committee for Structural Concrete (DAfStb) regulate by prescriptive measures against damaging 
ASR in structural elements made of reinforced and pre-stressed concrete in accordance with DIN EN 206-1 and DIN 1045-2. Since 2007, it also offers the opportunity for verification by ASR-performancetests.

\subsubsection{Concrete road pavement}

To avoid ASR damage of concrete road pavements on Federal highways, the Federal Ministry for Transport, Building and Urban Development published the General Circular on Road Construction (ARS) No. $04 / 2013$ in 2013. For road pavements of defined load classes, the resistance of the concrete mix or of the coarse aggregates is to be verified. In the last case, the coarse aggregates are used in a standardised worstcase concrete mix for concrete pavements. The concrete has to be tested with the methods " $60{ }^{\circ} \mathrm{C}$ concrete test with external alkali supply" or the "alternating climate storage". Both methods are described as "Technical testing regulations for base courses with hydraulic binders and concrete pavements".

\subsubsection{Airports}

Airports in Germany normally request certification of a sufficient ASR-resistance for concrete constructions that are exposed to airport-specific de-icing chemicals. Therefore, concrete mixes for aircraft operating areas (e.g. runways, taxiways and aprons of airports) and precast elements are tested by means of an ASRperformance-test with external alkali supply from deicer-containing solutions.

\subsubsection{Hydraulic engineering structures}

The Federal Department of Transport stipulates specific regulations for hydraulic engineering structures to mitigate deleterious alkali-silica reaction (Directive WS 13/5257.6/2). Beside the prescriptive specification it also gives the option of verifications by means of ASR-performance-test if specific alkalireactive aggregates are going to be used.

\subsubsection{Railway sleepers}

In addition to prescriptive requirements on the aggregate and the cement, the ASR-potential of concrete mixes for railway sleepers should be assessed by ASRperformance-tests. The test setup is described by the currently informative Deutsche-Bahn-Standard DBS 918 143, Annex G.

\subsection{France}

\subsubsection{History of development of the test}

The concrete performance test at $60{ }^{\circ} \mathrm{C}$ and $100 \% \mathrm{RH}$ was developed during the years 1989 to 1991 and was first referred to in the "Provisional Recommendations for the Prevention of Damage by the Alkali-Aggregate Reaction" released by LCPC (Central Laboratory for Roads and Bridges) in 1991 (in chapter 6 and Annex $\mathrm{H})$. An article describing this performance test on a concrete composition was published by Bolotte at the ICAAR conference 1992 held in London in 1992/1/.

This performance test was then included in the final "Recommendations for the Prevention of Damage by the Alkali-Aggregate Reaction" published by LCPC in 1994: in that document, the use of this test was detailed in Chapter 6 and the testing procedure was described in Appendix G. At that time, the expansion threshold of $0.02 \%$ was fixed in the Recommendations for a test duration of 3 months or 5 months, depending on the type of aggregate; this expansion value was decided upon after calibration on concrete mix designs used in existing structures damaged or not damaged by AAR in France.

Then, the performance procedure was standardized by AFNOR under the number NF P18-454 in December 2004/2/. At the same time the thresholds and the duration of the test which were not at the same level of consensus were fixed in a provisional standard by AFNOR under the number FD P18-456/3/; this document included also concrete compositions with mineral additions and for this type of concrete the duration of the test was set to 12 months with an expansion threshold of $0.03 \%$.

These two standards are now referred to in the standard FD P 18-464 entitled "Concrete-Dispositions to prevent AAR phenomena" published by AFNOR in April 2014/4/and which replaced the LCPC Recommendations of 1994. 


\subsubsection{Use of the test}

In France, the concrete performance test is used as a possibility to prevent AAR-induced damages in new structures, for level B of prevention (most of buildings and civil engineering structures located in a humid environment-see Table 11). As such, the test is used for jobsite concrete, but because of its rather long duration, the test in generally used for checking that a given concrete composition is suitable, or in case of doubt when for example an aggregate is at the border between a non-reactive and a reactive aggregate.

This test is also used for the level $\mathrm{C}$ of prevention (exceptional structures like great dams, nuclear vessels, tunnels, exceptional bridges, monuments, etc.) for which non-reactive (NR) aggregates and potentially reactive aggregates with pessimum effect (PRP) are specified; but when NR and PRP aggregates are not available, an exemption allows for the use of a performance test to determine the alkali threshold for a particular aggregate/cement combination (with aggregate representative of the one used in the exceptional structure) and with the application of a safety factor to the alkali level actually used in the exceptional structure. The alkali threshold is the lowest alkali level in the concrete at which a damaging expansion is found in tests. Once the alkali threshold has been determined the job mix can be designed with a safety factor in the form of a lower alkali level. Depending on the criticality of the structure and the confidence with which the alkali threshold has been determined, a safety factor can be applied by reducing the alkali level in the job mix by between 1.0 and $2.0 \mathrm{~kg} / \mathrm{m}^{3}$ $\mathrm{Na}_{2} \mathrm{O}_{\text {eq. }}$. below the alkali threshold. This safety factor will also give some protection against possible longterm alkali contribution by aggregates. For exceptional structures, there is normally sufficient time to design or to validate a suitable concrete composition

Table 11 Determination of the prevention level A, B and C

\begin{tabular}{llll}
\hline Structure category & \multicolumn{4}{l}{ Exposure class } \\
\cline { 2 - 4 } & XAR1 & XAR2 & XAR3 \\
\hline I & A & A & A \\
II & A & B & B \\
III & C & C & C \\
\hline
\end{tabular}

with such a concrete performance test applied on the real concrete.

\subsubsection{Some details on the test}

The performance test is applied on concrete produced with the materials delivered by the client according to the mix design given by the client for the specific jobsite concrete. Three concrete prisms $\left(70 \times 70 \times 282 \mathrm{~mm}^{3}\right)$ are produced and stored at a temperature of $60^{\circ} \mathrm{C}$ and a relative humidity of $\sim$ $100 \%$; this is achieved using containers holding the three prisms on a grid above water. The containers themselves are placed in a reactor that actively controls temperature and relative humidity. Length and mass changes are determined every four weeks. The limit value of expansion is defined at $0.02 \%$ after 20 weeks. If a concrete mix exceeds this value, a second analysis is performed after 48 weeks, where the limit value is defined at $0.03 \%$. The analysis is actually more complex than described here in short, as the gradient of the expansion and the expansion values of the individual prisms are also taken into account $/ 3 /$. The active alkali content of the used cement and mineral additions has to be determined before producing the concrete. Depending on the fluctuations of the alkali content during cement production and the value of the used batch, boosting with $\mathrm{NaOH}$ may be required.

The test has been well-accepted by the French construction industry for about 20 years. Since 1994, the year of application of the LCPC Recommendations, no new case of AAR has been detected in France.

\subsubsection{Source of information used in Sect. 9.4}

1. B. Bolette, Development of an accelerated performance test on concrete for evaluating its resistance to AAR-9th International Conference on AAR in concrete (London 27-31 July 1992).

2. AFNOR NF P18-454, Béton-Réactivité d'une formule de béton vis-à-vis de l'alcali-réactionEssai de performance, Association Française de Normalisation, Paris, December 2004. (« Reactivity of a concrete formula with regard to the alkali-aggregate reaction») 
3. AFNOR FD P18-456, Béton-Réactivité d'une formule de béton vis-à-vis de l'alcali-réactionCritères d'interprétation des résultats de l'essai de performance, Association Française de Normalisation, Paris, December 2004 ("Interpretation criteria for NF P 18-454")

4. AFNOR FD P18-464, Béton-Dispositions pour prévenir les phénomènes d'alcali-réaction, Association Française de Normalisation, Paris, Avril 2014.

\subsection{Switzerland}

In Switzerland, a concrete performance test is used with the goal of preventing AAR-induced damages in new structures. As such, the test is used for jobsite concrete. The test procedure, the application of the test and the use of the test results are described in the SIA guideline MB 2042 since 2012/1/. However, it has to be mentioned that the test has been in use since about 2000. In addition to the concrete performance test, an ultra-accelerated test to identify potentially reactive aggregates is described in the guidelines as well.

The concrete performance test is based on the French standard P18-454/2/and is similar to AAR-4.1/ $3 /$. The active alkali content of the used cement and mineral additions has to be determined before producing the concrete. Depending on the fluctuations of the alkali content during cement production and the value of the used batch, boosting with $\mathrm{NaOH}$ may be required. Boosting is always required for mineral additions. Concrete is produced with the materials delivered by the client according to the mix design given by the client for the specific jobsite concrete. Three concrete prisms $\left(70 \times 70 \times 282 \mathrm{~mm}^{3}\right)$ are produced and stored at a temperature of $60{ }^{\circ} \mathrm{C}$ and a relative humidity of $\sim 100 \%$ : this is achieved using containers holding the three prisms on a grid above water. The containers themselves are placed in a reactor that actively controls temperature and relative humidity. Length and mass changes are determined every four weeks. The limit value of expansion is defined at $0.02 \%$ after 20 weeks. If a concrete exceeds this value, a second analysis is performed after 48 weeks, where the limit value is defined at $0.03 \%$. The analysis is actually more complex than described here in short, as the gradient of the expansion and the values of the single prisms are taken into account as well/1/.

Whether a concrete performance test is necessary or not is defined by its prevention class (Table 12). The prevention class is dependent on the risk class (importance of a given structure) and the environmental class (mainly dependent on the ambient humidity and its fluctuations). No test is required for prevention class P1. Whether a test is necessary in prevention class $\mathrm{P} 2$ depends on the long-term experience and the result of the ultra-accelerated microbar test. But as about $95 \%$ of the Swiss concrete aggregates are potentially reactive/4/, a concrete performance test is usually conducted for prevention class $\mathrm{P} 2$. In prevention class $\mathrm{P} 3$, the consultation of an expert is mandatory in addition to the requirements of prevention class $\mathrm{P} 2$. Moreover, additional measures in the planning stage, in the call for bids and during construction have to be outlined. If the test criteria of the concrete performance test are not met, the mix design of the concrete has to be changed and the new mix design has to be tested again. If the concrete passes the test, it is classified as resistant to AAR.

The test result is valid for 5 years and can be applied for other concrete mixtures as well, if the requirements listed in Table 13 are fulfilled.

The test is well accepted in the Swiss construction industry. Currently, the Swiss standard SIA 262-1 containing the test protocols for concrete is under revision and the concrete performance test will be included, elevating it from a guideline to a standard.

The transferability of the test results to concrete structures has been demonstrated in/4,5/.

\subsubsection{Source of information used in Sect. 9.5}

1. SIA Merkblatt 2042. Vorbeugung von Schäden durch die Alkali-Aggregat-Reaktion (AAR) bei

Table 12 Definition of the prevention classes P1, P2 and P3

\begin{tabular}{llll}
\hline Risk class & \multicolumn{3}{l}{ Environmental class } \\
\cline { 2 - 4 } & $\mathrm{U} 1$ & $\mathrm{U} 2$ & $\mathrm{U} 3$ \\
\hline $\mathrm{R} 1$ & $\mathrm{P} 1$ & $\mathrm{P} 1$ & $\mathrm{P} 1$ \\
$\mathrm{R} 2$ & $\mathrm{P} 1$ & $\mathrm{P} 2$ & $\mathrm{P} 2$ \\
$\mathrm{R} 3$ & $\mathrm{P} 2$ & $\mathrm{P} 2$ & $\mathrm{P} 3$ \\
\hline
\end{tabular}


Table 13 Criteria for the transferability of the test results

\begin{tabular}{ll}
$\begin{array}{l}\text { Concrete } \\
\text { components }\end{array}$ & Boundary conditions, requirements \\
\hline Aggregates & $\begin{array}{l}\text { (a) The aggregates are produced in the same quarry and have a comparable petrographic composition } \\
\text { (b) If the amount of crushed aggregates in the sand is changed (e.g. }>50 \% \text { ), an analysis has to be conducted by } \\
\text { an expert }\end{array}$ \\
Origin of cement & $\begin{array}{l}\text { The cement is produced in the same cement plant } \\
\text { Cement type }\end{array}$ \\
Cement content & $\begin{array}{l}\text { The concrete contains the same cement with the same strength class } \\
\text { w/c }\end{array}$ \\
Mineral additions & $\begin{array}{l}\text { The variation of the w/c is lower than } \pm 0.05 \\
\text { mixtures does not vary of more than } \pm 10 \mathrm{~kg} / \mathrm{m}^{3}\end{array}$ \\
Admixtures & $\begin{array}{l}\text { Changes in composition and dosage of the same type of admixture (e.g., superplasticizer) are permitted, as long } \\
\text { as their contribution to the alkali level of the concrete is not higher than } 50 \% \text { compared to their original }\end{array}$ \\
& content
\end{tabular}

This is a shortened version of the Table published in/1/

Betonbauten. Schweizerischer Ingenieur- und Architektenverein, Zürich, 2012.

2. AFNOR P18-454, Réactivité d'une formule de béton vis-à-vis de l'alcali-réaction (essaie de performance), Association Française de Normalisation, Paris, 2004.

3. Nixon PJ, Sims I. RILEM Recommended Test Method: AAR-4.1-Detection of Potential AlkaliReactivity $-60^{\circ} \mathrm{C}$ Test Method for Aggregate Combinations Using Concrete Prisms. In RILEM Recommendations for the Prevention of Damage by Alkali-Aggregate Reactions in New Concrete Structures, Springer Netherlands, 2016, 99-116.

4. Merz C, Leemann A, Validierung der AARPrüfungen für Neubau und Instandsetzung, ASTRA-Bericht. AGB 2005/023 und AGB 2006/003, Bern, 2012.

5. Leemann A, Merz C. An attempt to validate the ultra-accelerated microbar and the concrete performance test with the degree of AAR-induced damage observed in concrete structures. Cement and Concrete Research. 2013, 49:29-37.

\subsection{Sweden}

In Sweden, testing of aggregate towards reaction with alkalis is regulated in SS 137,003:2015, the Swedish application standard to EN 206:2013. Since the last edition, released in 2015, SS 137,003 allows the use of aggregate that exhibited potential for alkali reaction in prior aggregate tests, if the aggregate in a specific concrete mix does not show any effects in a performance test according to a method described in the CBI report 4:92. The method in that report is an expansion test on concrete, which is immersed at $50{ }^{\circ} \mathrm{C}$ in a sodium chloride solution. The tested concrete has the same components as the concrete used for a specific construction project, but with a given mix design and water/binder ratio. The method is applied with respect to the exposure of concrete to de-icing salts in road infrastructures.

As per 2019, the implementation of the forthcoming new RILEM recommendations for performance testing of concrete towards ASR is being investigated. The test method described in the CBI report 4:92 can be considered as a transitional method. The Swedish ASR committee is writing a national guideline for ASR, which includes performance test criteria and methods and will include the new RILEM methods. In future editions, the Swedish standard SS 137,003 will refer to the Swedish ASR guideline.

\section{Annex C: Alkalis release from aggregates}

(Amendment to Sect. 3).

Some aggregates contain minerals containing alkalis that may be released under the applied testing 
conditions and possibly also under ambient conditions in field. Testing methods for determining, and especially for validating, practical implications for testing and lab/field correlation (for establishing limit values), is still subject to research.

For practical use, the effect of the release of such alkalis may implicitly have been taken into account when applying observations from the field to establish testing limit values. This, however, assumes that adequate field investigations comprising the type of aggregates have been conducted, and that limit values are not "transferred" from other segments/areas.

\section{Declarations}

Conflict of interest The authors declare that they have no conflict of interest.

\section{References}

\section{General}

1. Nixon PJ, Sims I (2016) RILEM Recommended test method AAR-4.1: detection of potential alkali-reactivity- $60{ }^{\circ} \mathrm{C}$ Test method for aggregate combinations using concrete prisms. In: RILEM Recommendations for the prevention of damage by alkali-aggregate reactions in new concrete structures. State-of-the-art reports 17, pp 99-116. https:// doi.org/10.1007/978-94-017-7252-5_6

2. Lindgård J, Nixon PJ, Borchers I, Schouenborg B, Wigum BJ, Haugen M, Akesson U (2010) The EU "Partner" project-European standard tests to prevent alkali reactions in aggregates. Cem Concr Res 40:611-635

3. Nixon PJ, Sims I (2016) RILEM Recommended test method AAR-0 - outline guide to the use of RILEM methods in the assessment of the alkali-reactivity potential of aggregates, RILEM Recommendations for the prevention of damage by alkali-aggregate reactions in new concrete structures. Stateof-the-art Rep 17:5-34

4. Borchers I, Lindgård J, Rønning TF, Wigum BJ (2021) RILEM recommended test method: AAR-11: determination of binder combinations for non-reactive mix design or the resistance to alkali-silica reaction of concrete mixes using concrete prisms $-60^{\circ} \mathrm{C}$ test method, (in press)

5. Nixon PJ, Sims I (2016) RILEM Recommended Specification AAR-7.1 -international specification to minimise damage from alkali reactions in concrete-Part 1: alkali silica reaction, RILEM Recommendations for the prevention of damage by alkali-aggregate reactions in new concrete structures. State-of-the-art Rep 17:131-145. https:// doi.org/10.1007/978-94-017-7252-5_8

6. Müller C, Seidel M, Böhm M, Stark J, Ludwig HM, Seyfarth K (2016) AKR-Untersuchungen für Fahrbahndecken aus Beton mit Waschbetonoberfläche. Berichte der
Bundesanstalt für Straßenwesen, Straßenbau S 90 https:// bast.opus.hbz-nrw.de/frontdoor/index/index/docId/1604

7. Müller C, Borchers I, Eickschen E (2013) Experience with ASR test methods: advice on obtaining practical evaluation criteria for performance testing and aggregate testing. Cem Int 11:86-93

8. Borchers I, Müller C (2014) Practical testing of the alkali reactivity of concrete compositions of the WF and WA moisture classes in ASR performance tests. Cem Int $12: 78-85$

\section{Standards}

9. NF P18-454:2004, Concrete-reactivity of a concrete formula with regard to the alkali-aggregate reaction-performance test

10. FD P18-456:2004, Concrete-reactivity of a concrete formula with regard to the alkali-aggregate reaction-criteria for interpretation of the performance test results

11. FGSV (2018) TP B-StB-technische Prüfvorschriften für Verkehrsflächenbefestigungen-Betonbauweisen: Teil 1.1.09 AKR-Potenzial und Dauerhaftigkeit von Beton (60 ${ }^{\circ} \mathrm{C}$-Betonversuch mit Alkalizufuhr), Köln

12. Bundesministerium für Verkehr, Bau und Stadtentwicklung (2013) Allgemeines Rundschreiben Straßenbau Nr. 04/2013 (kurz ARS 04/2013) und Anlage zum ARS: vermeidung von Schäden an Fahrbahndecken aus Beton in Folge von AlkaliKieselsäure-Reaktion (AKR), Bonn

13. DBS 918143 (2021) Technische Lieferbedingungen Gleisund Weichenschwellen aus Beton für Schotteroberbau (Scho) und Feste Fahrbahn (FF). DB Netz AG, Frankfurt/ Main

14. ASTM C136/C136M-19, Standard test method for the sieve analysis of fine and coarse aggregates

15. EN 480-1:2014, Admixtures for concrete, mortar and grout. Test methods. Reference concrete and reference mortar for testing

16. EN 12390-2:2019, Testing hardened concrete. Making and curing specimens for strength tests

17. ASTM C192/C192M-19, Standard practice for making and curing concrete test specimens in the laboratory

18. EN 197-1:2011, Cement. Composition, specifications and conformity criteria for common cements

19. ASTM C150/C150M-19a, Standard specification for Portland cement

20. EN 12620:2002+A1:2008, Aggregates for concrete

21. ASTM C33/C33M-18, Standard specification for concrete aggregates

22. EN 1097-6:2013, tests for mechanical and physical properties of aggregates. Determination of particle density and water absorption

23. ASTM C127-15, Standard test method for relative density (specific gravity), and absorption of coarse aggregate

24. ISO 7033:1987, Fine and coarse aggregates for concreteDetermination of the particle mass-per-volume and water absorption-Pycnometer method

25. ASTM C128-15, Standard test method for relative density (specific gravity), and absorption of fine aggregate 
26. EN 1097-5:2008, Tests for mechanical and physical properties of aggregates. Determination of water content by drying in a ventilated oven

27. ASTM C566-19, Standard test method for total evaporable moisture content of aggregate by drying.

28. EN 12350-7:2019, Testing fresh concrete. Air content. Pressure methods

29. ASTM C1170/1170M-14e1, Standard test method for determining consistency and density of roller-compacted concrete using a vibrating table
30. EN 12350-6:2019, Testing fresh concrete. Density

31. ASTM C173/C173M-16, Standard test method for air content of freshly mixed concrete by the volumetric method

32. ASTM C231/C231M-17a, Standard test method for air content of freshly mixed concrete by the pressure method

Publisher's Note Springer Nature remains neutral with regard to jurisdictional claims in published maps and institutional affiliations. 